\title{
Bony lesions in early tetrapods and the evolution of mineralized tissue repair
}

\author{
Eva C. Herbst (D), Michael Doube (D), Timothy R. Smithson, Jennifer A. Clack, \\ and John R. Hutchinson (D)
}

\begin{abstract}
Bone healing is an important survival mechanism, allowing vertebrates to recover from injury and disease. Here we describe newly recognized paleopathologies in the hindlimbs of the early tetrapods Crassigyrinus scoticus and Eoherpeton watsoni from the early Carboniferous of Cowdenbeath, Scotland. These pathologies are among the oldest known instances of bone healing in tetrapod limb bones in the fossil record (about $325 \mathrm{Ma}$ ). X-ray microtomographic imaging of the internal bone structure of these lesions shows that they are characterized by a mass of trabecular bone separated from the shaft's trabeculae by a layer of cortical bone. We frame these paleopathologies in an evolutionary context, including additional data on bone healing and its pathways across extinct and extant sarcopterygians. These data allowed us to synthesize information on cell-mediated repair of bone and other mineralized tissues in all vertebrates, to reconstruct the evolutionary history of skeletal tissue repair mechanisms. We conclude that bone healing is ancestral for sarcopterygians. Furthermore, other mineralized tissues (aspidin and dentine) were also capable of healing and remodeling early in vertebrate evolution, suggesting that these repair mechanisms are synapomorphies of vertebrate mineralized tissues. The evidence for remodeling and healing in all of these tissues appears concurrently, so in addition to healing, these early vertebrates had the capacity to restore structure and strength by remodeling their skeletons. Healing appears to be an inherent property of these mineralized tissues, and its linkage to their remodeling capacity has previously been underappreciated.
\end{abstract}

Eva C. Herbst* and John R. Hutchinson. Structure and Motion Laboratory, Royal Veterinary College, Hawkshead Lane, Hatfield, Hertfordshire AL9 7TA, United Kingdom. E-mail: eherbst@rvc.ac.uk, jhutchinson@rvc.ac.uk

Michael Doube. Department of Infectious Diseases and Public Health, City University of Hong Kong, Tat Chee Avenue, Kowloon, Hong Kong. E-mail: mdoube@cityu.edu.hk

Timothy R. Smithson and Jennifer A Clack. University Museum of Zoology, Cambridge, Downing Street, Cambridge, CB2 3EJ, United Kingdom.E-mail: ts556@cam.ac.uk, jac18@cam.ac.uk

Accepted: 13 August 2019

First published online: 27 September 2019

*Correspondence to: Eva C. Herbst, eherbst@rvc.ac.uk.

Data available from the Dryad Digital Repository: https://doi.org/10.5061/dryad.30kp1qg; and Figshare

Digital Repository: https://doi.org/10.6084/m9.figshare.9211643

\section{Introduction}

Bones have a remarkable ability to heal after traumatic injury and in the face of infectious, neoplastic, and other insults. Up to half of juvenile humans experience and survive bone fracture (Jenkins et al. 2018). Wild animals such as hawks, bottle-nosed dolphins, urban foxes, and serrasalmid fish (the group including piranhas) have high rates of fracture incidence and survival (de Smet 1977; Harris 1978; Roth et al. 2002; Kolmann et al. 2018). In human and veterinary medicine, fracture repair may be enhanced by supporting bones with splints, casts, slings, surgical implants, and medication; wild animals are not afforded such care and must heal by themselves if they are to regain competitive function. Despite its broad distribution in extant taxa and clear role in enhancing evolutionary fitness within and across species, an evolutionary context for bone healing has not yet been elucidated.

The broad category of bone repair may be subdivided into several different categories: regeneration, nonregenerative large-scale healing, remodeling, and biophysical annealing (Fig. 1). In regeneration (Fig. 1A), whole limb, tail, and fin segments regrow via the formation of a blastema, which comprises dedifferentiated cells (Egawa et al. 2014; see Akimenko et al. [2003] and Akimenko and Smith [2007] for fin regeneration). We divide nonregenerative large-scale healing into three subcategories: 
BONE REPAIR MECHANISMS
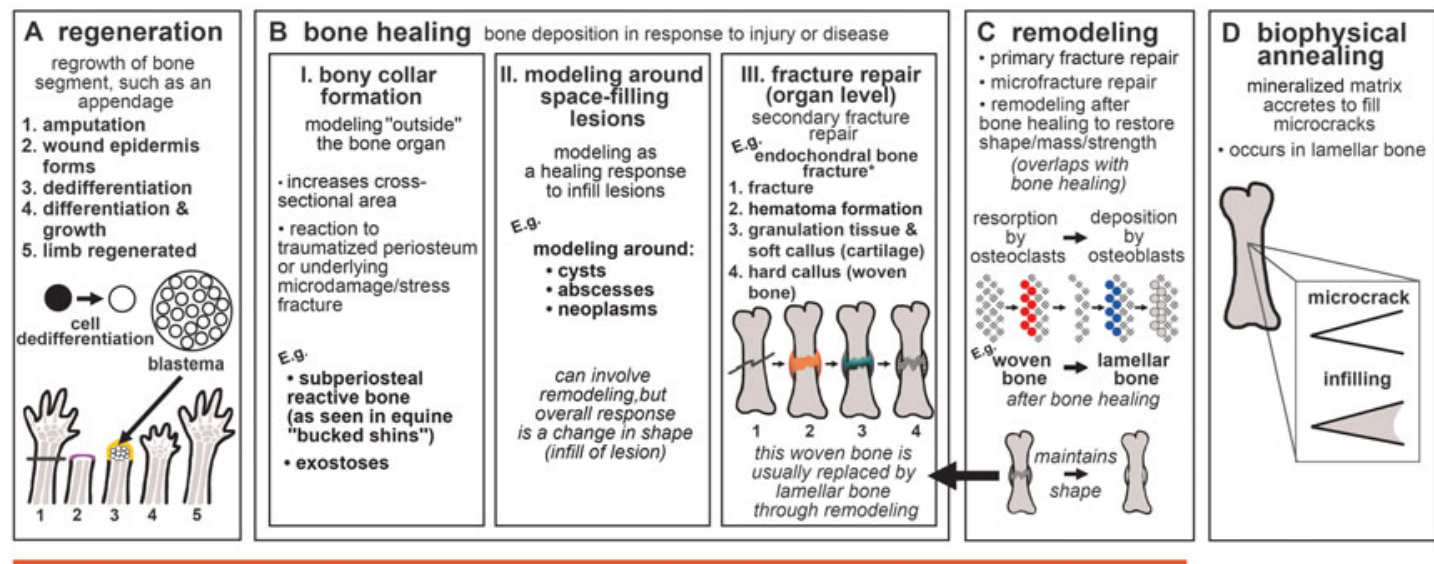

Terms

cell mediated

(2) blastema: mass of multipotent cells
in vertebrate regeneration, the source of these cells is dedifferentation of other cells - osteoblast: cell that deposits bone

- osteoclast: cell that resorbs bone

- woven bone (or primary bone): irregularly deposited bone, also known as primary bone - lamellar bone (or secondary bone): ordered bone, stronger
than woven bone
- wound epidermis: healing reponse by migrating epidermal cells
apical epidermal cap: distal signaling center for growth

FIGURE 1. Generalized schematic of bone repair mechanisms: A, regeneration; B, bone healing; C, remodeling; and D, biophysical annealing. *For healing of dermal bone in various taxa (via cartilaginous or fibrous callus formation), see Moss (1962), Irwin and Ferguson (1986), and Geurtzen et al. (2014). For endochondral healing mechanisms with surgical fixation, see Shapiro (2008).

fracture repair, bony collar formation (subperiosteal reactive bone and exostoses), and modeling and remodeling around space-filled lesions (such as cysts, abscesses, and neoplasms), which for brevity we refer to collectively as bone healing (Fig. 1B). Bony collar formation is modeling "outside" the bone organ, by the formation of subperiosteal reactive bone and exostoses. An example of bony collar formation is in equine "bucked shins," where bone forms in response to high-strain cyclic injury (Nunamaker 2002). Modeling and remodeling around space-filling lesions help heal bone in response to disease and infection. Here we use the term fracture repair only to refer to the healing processes that occur after gross organ breakage into separate fragments. This "secondary" or "indirect" fracture repair process is characterized by rapid fibrous/cartilaginous callus formation that closes the fracture gap and stabilizes interfragmentary movement (Shapiro 2008; Marsell and Einhorn 2011). In contrast, incomplete and fatigue ("stress") fractures that are stable and lack a fracture gap heal by secondary osteonal remodeling that fixes the intracortical cracks and/or by deposition of a collar of subperiosteal woven bone (Uthgennant et al. 2007; Shapiro 2008; Marsell and Einhorn 2011). We do not include healing of stress fractures or microfractures in the category of fracture repair, because the healing process of stress and microfractures omits fibrocartilaginous callus formation.

Bone healing usually incorporates remodeling. During fracture repair, woven bone in the callus is removed and replaced by mature lamellar bone, restoring the strength of the bone organ (Shapiro 2008). In our terminology (following Frost 1991), remodeling refers to the process of bone resorption by osteoclasts and deposition by osteoblasts without an overall change in organ shape (i.e., formation follows resorption on the same surface), and modeling refers to unbalanced formation and resorption, leading to a net change in organ shape (e.g., callus formation) or size (e.g., during growth) (Fig. 1B,C). Modeling and remodeling function during normal bone growth; modeling increases bone size during development, and modeling and remodeling enable growth to occur while keeping dynamic strains consistent (Biewener et al. 1986; Frost 1991). Furthermore, 
bone remodeling can function in mineral homeostasis (Doherty et al. 2015). Remodeling repairs microfractures in cortical bone (Burr 1993; Mori and Burr 1993; Bentolila et al. 1998). Bone's healing response can consist of tissue formation only (i.e., modeling), for example, subperiosteal bone deposition forming a bony collar. Remodeling is not always necessary to reconnect two fractured segments or to infill a lesion, but is advantageous in the healing pathway, because it re-establishes full strength in the healed structure (Shapiro 2008). Due to its tissue maintenance function and ability to repair microfracture and stress fracture independently, we place remodeling in its own category within bone repair, while recognizing its contribution to the later stages of fracture repair. Modeling around space-filling lesions, and bony collar formation, can also be followed by remodeling. However, the subcategories of bone healing are united by the characteristic that they are modeling processes, with a net change in organ shape (e.g., formation of a callus or collar or infilling of a lesion). Therefore, we do not include remodeling as a subcategory of bone healing.

Microfractures may repair through biophysical annealing (Fig. 1D). In biophysical annealing, mineralized matrix accretes within microcracks (Boyde 2003), presumably by passive precipitation of hydroxyapatite and other moieties from bone tissue fluid onto exposed matrix surfaces, as occurs in acellular dental enamel. The exact mechanism of biophysical annealing is not known, but it does not involve remodeling or osteocyte apoptosis. Osteocytes might have an indirect role by modulating fluid composition in the surrounding lacunar canalicular space (Herman et al. 2010; SerefFerlengez et al. 2014).

We refer to regeneration, bone healing, and remodeling as being cell-mediated, because they involve the resorption of bone by osteoclasts and deposition of bone by osteoblasts, whereas biophysical annealing lacks obvious cellular control. All three cell-mediated bone repair processes, but not biophysical annealing, have been discovered in fossils (Capasso et al. 1996; Tanke and Currie 1998; Anné et al. 2014; Fröbisch et al. 2014, 2015; Stilson et al. 2016; Pardo-Pérez et al. 2018; van der Vos et al.
2018). Paleopathologies can provide insight into the evolution of bone repair, because paleopathologies are direct evidence of bone's response to insult.

Although it is often difficult to determine the exact etiology of a paleopathology (Moodie 1917), bone healing, regeneration, and remodeling can be distinguished from one another in the fossil record. For example, the presence of a fracture callus in a fossil indicates that the animal survived the fracture and started the fracture repair process. Bone healing may also manifest as an unusual bone formation in response to nonfracture insult or disease; sometimes it is not possible to specify the type of bone healing (response to fracture vs. other disease). Remodeling can be identified by the presence of secondary osteons. Microcracks (and hence, their repair) are difficult to identify in the fossil record; however, there is evidence of remodeling as part of growth (Giles et al. 2013) and as a late phase of fracture repair in fossils (Lingham-Soliar 2004; Zammit and Kear 2011; Pardo-Pérez et al. 2018).

Paleopathological evidence of regeneration consists of unique limb patterning associated with abnormal regeneration. Fröbisch et al. (2014) described limb regeneration in the fossil record in the 300-million-year-old temnospondyl amphibian Micromelerpeton. Tail regeneration in the microsaurs Hyloplesion and Microbrachis resembles that of extant salamanders, and these early tetrapods may also have been able to regenerate limbs (Fröbisch et al. 2015; van der Vos et al. 2018). Nogueira et al. (2016) reported that gene expression is similar in extant salamander limb and lungfish fin regeneration. All these studies analyzed their findings in a broader phylogenetic context, inferring that regeneration of both tails and appendages (fins/limbs) is ancestral for tetrapods, perhaps even a synapomorphy of all sarcopterygians or even all osteichthyans.

Here our goal is to answer the question of when bone healing mechanisms evolved by synthesizing available data, similar to the studies of regeneration noted. We describe new evidence of bone healing in the hindlimbs of the early tetrapods Crassigyrinus scoticus and Eoherpeton watsoni from the early Carboniferous. Along with the slightly older Ossinodus (Warren 
and Ptasznik 2002; Bishop et al. 2015), these are the earliest known instances of healing in tetrapods. We considered these pathologies in a phylogenetic context of extinct and extant vertebrates to reconstruct the evolution of nonregenerative repair in bone.

Our investigation began with bone healing in limb (endochondral) bones of tetrapods and expanded to include dermal bones. While dermal and endochondral bones are characterized by different ossification pathways (endochondral bones form via a cartilage precursor), both of these types of bone arise from the activity of osteoblasts, and the bone formed does not differ between the two mechanisms (Shapiro 2008). Furthermore, endochondral bones such as limb bones undergo subperiosteal intramembranous ossification in the diaphysis and part of the metaphysis during development, and intramembranous ossification also occurs during fracture repair of these bones (Hall 2005; Shapiro 2008). In birds and mammals, intramembranous (dermal) bones form secondary cartilage during fracture repair (Irwin and Ferguson 1986). The loading environment seems to have a strong influence on the type of bone ossification, during both development and fracture repair (Shapiro 2008 and references therein). Evolutionarily, ancestrally endochondral bones can become membrane bones in some taxa, such as the orbitosphenoid of Leposternon (Hall 2005).

Bone can also be categorized as belonging to the endoskeleton or exoskeleton. While all bones in the exoskeleton are dermal and ossify intramembranously, the endoskeleton ossifies through both endochondral ossification (e.g., in limb bones) and intramembranous ossification (in membrane bones such as many cranial elements). It was traditionally thought that the exoskeleton developed from neural crest cells and the endoskeleton developed from mesoderm (Hirasawa and Kuratani 2015). However, recent research has shown that the endoskeleton and exoskeleton cannot be distinguished by ossification type or embryonic origins. For example, mouse parietals (part of the exoskeleton) have a mesodermal origin (Jiang et al. 2002). Furthermore, in the medaka (Oryzias), the mesoderm is the embryonic origin of the trunk exoskeleton (scales and fin rays).
Therefore, the earliest exoskeletons may have been derived from both neural crest cells and mesoderm (Shimada et al. 2013). These discoveries support the link between dermal bones and endochondral bones. Although tetrapod limb bones are endochondral and endoskeletal, and fish fin rays are dermal bones and are part of the exoskeleton, both share a mesodermal origin. Embryonic origin therefore does not separate the endoskeleton and the exoskeleton (Hall 2014; Hirasawa and Kuratani 2015). In light of the overlapping characteristics of ossification pattern and embryonic origin in the endoskeleton and exoskeleton, we investigated endochondral and dermal bones of both the endo- and exoskeleton.

We compared bone healing with regeneration to examine the evolution of these different repair mechanisms. Furthermore, we investigated remodeling capacities to determine whether remodeling and healing evolved concurrently. In addition to our first aim of reconstructing how bone healing evolved and how it relates to regeneration and remodeling, our second aim was to reconstruct the evolution of healing in other skeletal tissues. We surveyed the fossil record of mineralized vertebrate skeletal tissues with evidence of healing and remodeling (bone, aspidin, dentine), including conodont mineralized tissues as an outgroup comparison with unusual convergent evolution of mineralized tissue repair. The early vertebrate exoskeleton evolved before the endoskeleton, and consisted of both bone (aspidin in heterostracans) and dentine (Donoghue et al. 2006; Hall and Witten 2007). Aspidin has recently been identified as acellular dermal bone based on spaces that were probably left behind by intrinsic collagen bundles, much like those found in teleosts (Keating et al. 2018). There is still debate about the evolution of mineralized tissues (Smith and Hall 1990; Donoghue and Sansom 2002; Donoghue et al. 2006; Hall and Witten 2007; Doherty et al. 2015; Hall 2015), but a recent evolutionary analysis showed that cellular bone evolved from aspidin at least twice in vertebrate evolution (Keating et al. 2018). Furthermore, Hall and Witten (2007) discussed the overlap in various characteristics of the different mineralized vertebrate skeletal tissues and the presence of intermediate tissues, concluding that a plastic 
skeletogenic cell, along with a skeletal resorbing cell, evolved with the first vertebrate mineralized skeletal tissues. We investigated whether healing of vertebrate skeletal tissues evolved early on in vertebrate evolution and whether evidence of healing and remodeling abilities coincide with one another in time and taxa.

Institutional Abbreviations.-NHMUK R, Natural History Museum, London, United Kingdom; NMS G, National Museums Scotland, Edinburgh, United Kingdom; QMF, Queensland Museum, Brisbane, Australia.

\section{Materials and Methods}

We investigated unusual bony features in the early tetrapods Crassigyrinus and Eoherpeton. All specimens are from the Dora Bonebed in the Limestone Coal Formation of the Clackmannan Group, Ammonoid Zone E1a of the Pendelian substage, Serpukhovian, Mississippian (Browne et al. 1999). The Dora site is near Cowdenbeath, Fife, Scotland. We studied several specimens (Supplementary Table 1) with one or more unusual features that we identified as likely pathologies. Only the Crassigyrinus ribs were previously described as pathological.

We imaged the bones with X-ray microtomography (XMT; Nikon Metrology XT $\mathrm{H}$ and HMX 225 ST, and Bruker Skyscan 1172) to investigate the internal structure, noting the qualitative density and distribution of cortical and trabecular bone (scan data available from the Figshare Digital Repository: https://doi. org $/ 10.6084 / \mathrm{m} 9$.figshare.9211643). The resulting scans were then segmented in Mimics 19.0 (Materialise, Leuven, Belgium) to remove the matrix, view cross sections of the internal anatomy, and create a 3D model of each bone. In one case, further image processing in Image (Schneider et al. 2012) was used to highlight the trabecular architecture (see Supplementary Text 3 for information on the macro).

Where possible (i.e., for the Crassigyrinus metatarsal and Eoherpeton right fibula), the external and internal morphology of the presumably pathological bone was compared with a normal bone from the same species and site. Where no comparative limb material existed, we used features associated with muscle attachment as an example of normal morphology with which we could compare the potentially pathological features.

We placed our results into a phylogenetic framework to examine the evolution of bone healing. Sarcopterygian evolutionary relationships were based on recent phylogenetic analyses (Zhu and Yu 2002; Ruta et al. 2003; Pyron and Wiens 2011; Chiari et al. 2012; Clack et al. 2016). We mapped all occurrences of bone healing in the fossil record onto the sarcopterygian phylogeny, recording fracture repair in extant animals as a proxy for bone healing ability and comparing these healing pathways and regeneration pathways in representatives of all major sarcopterygian taxa.

We also investigated bone healing and regeneration in extant actinopterygians (including acellular bone in teleosts), and then broadened our phylogenetic survey to all vertebrates to map the occurrence of healing in all mineralized tissues. The vertebrate phylogenetic tree was based on Gess et al. (2006), whose analysis found "agnathans" to be polyphyletic and placed osteostracans as the sister taxon to gnathostomes. The phylogenetic placement of acanthodians is contentious; phylogenetic analyses have placed Acanthodes and most other acanthodians either as stem osteichthyans or stem chondrichthyans, the latter being supported by more recent analyses and reanalysis of Acanthodes anatomy (Brazeau 2009; Brazeau and de Winter 2015; Giles et al. 2015). Regardless, all of these analyses placed Doliodus within Chondrichthyes, so we classified it as such for our phylogenetic analysis. We omitted hagfish and lampreys from our phylogeny, because they do not have mineralized tissues.

\section{Results}

First, we present new observations of paleopathologies in two early tetrapods, Crassigyrinus and Eoherpeton ("Pathologies in Early Tetrapods" section). Next, we place these paleopathologies in the context of a synthesis of published data on bone healing, regeneration, and remodeling in extinct and extant taxa ("Bone Healing, Remodeling, and Regeneration" section). For bone healing in extant taxa, we used fracture repair as a proxy for bone healing (fracture repair is a type of bone healing, and 
therefore indicates a taxon's ability to respond to damage by blastic activity to repair bone tissue). In our synthesis, we included remodeling related to both growth and healing, because they involve the same mechanism, and our aim was to determine whether occurrences of bone healing and remodeling are linked.

We then conducted a similar synthesis of healing and remodeling in aspidin ("Aspidin Healing and Remodeling" section) and dentine ("Dentine Healing and Remodeling" section) to examine whether there is a link between the evolution of these two processes in other mineralized tissues. We do not discuss regeneration for aspidin and dentine, because in our terminology regeneration is distinct from bone healing and refers to the formation of a body segment via the dedifferentiation of cells and the recapitulation of developmental processes. In the fossil record, regeneration has been reported only for sarcopterygian bone, and the identification in fossils is based on comparison with salamander regeneration abnormalities. While Halstead (who also published under the name "Tarlo") reported "regeneration" in heterostracan dentine, this term refers to healing via replacement of dentine tubercles (Halstead 1969, 1973). Similarly, Lebedev et al. (2009) used "regeneration" to mean regrowth of tissue in response to injury, the process that we refer to as "bone healing."

Enamel and cartilage are not included in our synthesis; although they are also skeletal tissues, we chose to omit them for the following reasons. Enamel is unable to remodel (Goodman and Rose 1994; Maas and Dumont 1999), and no fracture or caries repair has been reported outside clinical intervention. Unmineralized cartilage does not preserve well in the fossil record, and although there is evidence of calcified cartilage in early vertebrates (Janvier et al. 2004), no evidence of healing or remodeling has been reported. The capacity for extant tetrapod cartilage to remodel is contentious, but it appears that neither complete remodeling nor full healing are possible (Jackson et al. 2001; Sharma et al. 2013). Even the cartilaginous skeleton of elasmobranchs does not remodel or heal (Ashhurst 2004; Johansson et al. 2004).

In the section on "Conodont Mineralized Tissues," we discuss conodont dental elements, which have been reported as the earliest vertebrate mineralized tissues in the fossil record and are known from the late Cambrian onward (Sansom et al. 1992). Unfortunately, the phylogenetic relationship of conodonts remains uncertain, and a recent study disputed the classification of conodonts as vertebrates (Turner et al. 2010). Conodont mineralized tissue is not homologous to enamel (Kemp 2002b; Turner et al. 2010; Murdock et al. 2013), despite prior reports (Sansom et al. 1992; Donoghue and Sansom 2002). Here we classify conodonts as an outgroup to vertebrates. Even recent studies that considered conodonts as vertebrates agreed that the tissues constituting dental elements evolved convergently with vertebrate mineralized tissues (Shirley et al. 2018). Investigating healing and remodeling in conodont dental elements can tell us whether certain mineralized tissue repair mechanisms are unique to vertebrate mineralized tissues.

Overall results of the phylogenetic syntheses are presented in "Phylogenetic Synthesis."

\section{Pathologies in Early Tetrapods}

XMT images revealed that the unusual growths on the Crassigyrinus hindlimb and ribs and Eoherpeton right fibula are pathological (Figs. 2-6). There is not enough evidence to discern exactly which disease or injury caused these lesions in Crassigyrinus and Eoherpeton, but the lesions are evidence of bone healing.

Crassigyrinus.-Two unusual protuberances are present on the hindlimb bones of Crassigyrinus. They are on the right tibia of block NMS G 1984.15.3 and on the left femur of block NMS G 1984.15.1 (see Supplementary Text 1 for more specimen information). Panchen and Smithson (1990) described these features as being unique to Crassigyrinus and interpreted them as possibly being the attachment sites for a ligament that prevented dislocation of the knee during swimming.

Crassigyrinus femur.-The protuberance on the Crassigyrinus femur is on the distal end of the ventral surface, near the knee joint (Fig. 2). It is a pitted protrusion that is rounded proximally and widens slightly where it meets the distal surface of the bone. The interior of this growth is composed of trabecular bone, which is separated from medullary trabecular 

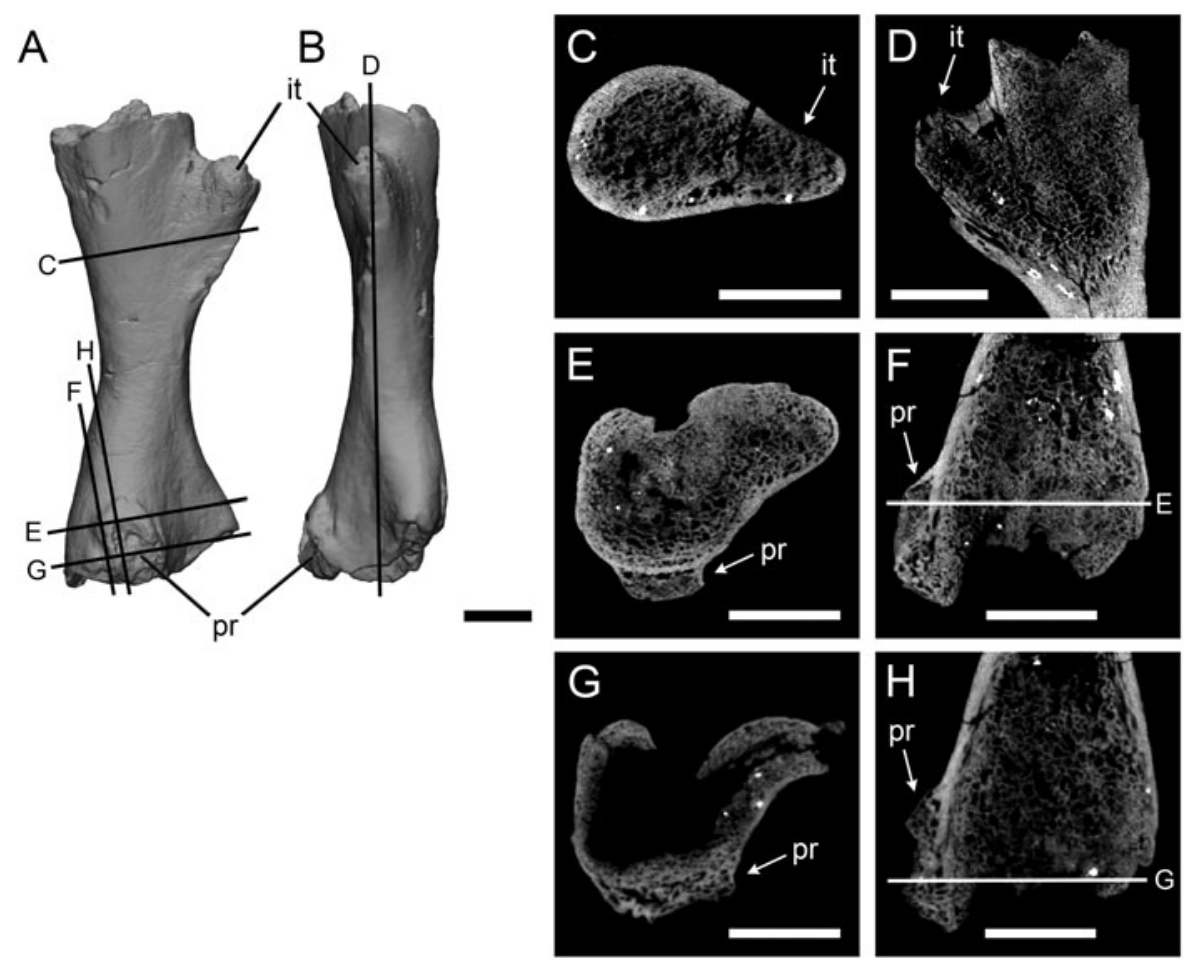

FiguRE 2. Crassigyrinus left femur in ventral (A) and anterior (B) views. Internal trochanter in transverse (C) and long-axis (D) sections; protuberance in transverse $(E, G)$ and long-axis $(F, H)$ sections. it, internal trochanter; pr, protuberance. Scale bars: $10 \mathrm{~mm}$.

bone by cortical bone. On the proximal end of the growth, some cortical bone modeling is evident on the exterior of the trabecular bone. The location of trabecular bone superficial to the cortex indicates that the growth is a pathology.

To confirm that this bone distribution is pathological and not characteristic of normal bony features in Crassigyrinus, we investigated the internal structure of the well-developed internal trochanter on the anterior side of the same bone. The internal trochanter is present in other early tetrapods and has been inferred to be a key muscle insertion site (Godfrey 1989; Molnar et al. 2018). Comparing the unusual growth with the internal trochanter allowed us to control for intraspecific and ontogenetic variation in bone structure, because the two features are on the same bone from the same individual. The cross sections revealed that while there is some anteroposterior change
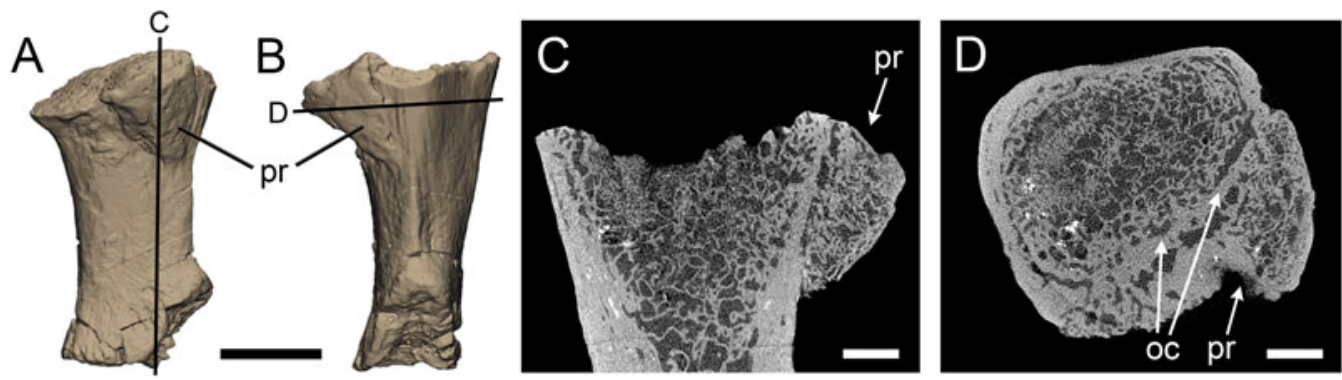

FIGURE 3. Crassigyrinus right tibia in medial (A) and posterior (B) views; protuberance in long-axis (C) and transverse (D) sections. oc, original cortex; pr, protuberance. Scale bars: $10 \mathrm{~mm}(\mathrm{~A}, \mathrm{~B}) ; 3 \mathrm{~mm}(\mathrm{C}, \mathrm{D})$. 

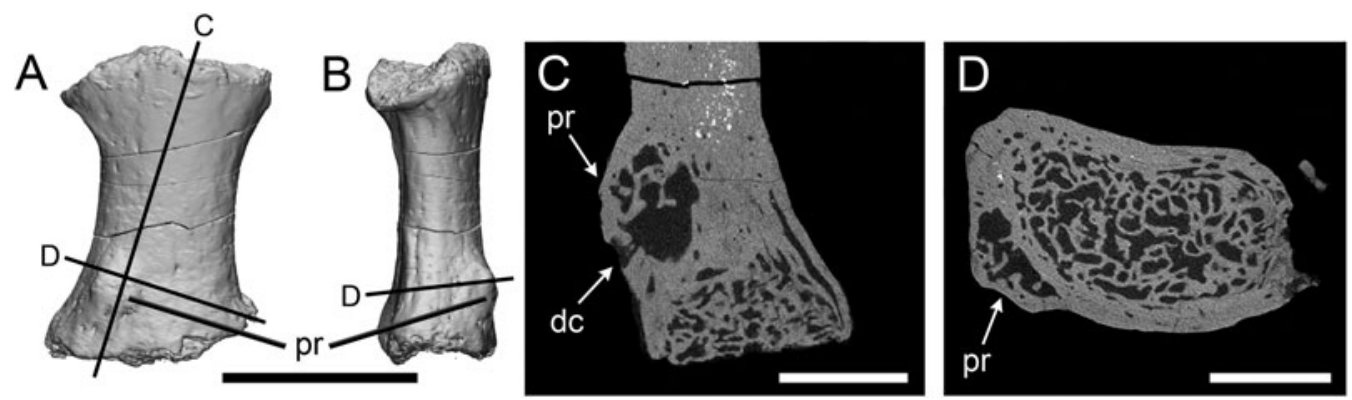

FIGURE 4. Crassigyrinus metatarsal in extensor (A) and medial or lateral (B) views; protuberance in long-axis (C) and transverse (D) cross sections. dc, drainage channel; pr, protuberance. Scale bars: $10 \mathrm{~mm}$ (A, B); $3 \mathrm{~mm}(\mathrm{C}, \mathrm{D})$.

in the density of the trabecular bony tissue, the trabecular bone of the internal trochanter is continuous with that of the femoral shaft (Fig. 2C,D). This is different from the protuberance, where there is a clear separation of the trabecular bone of the protuberance from the bone shaft, demarcated by cortical bone (Fig. 2E,F). This difference between the growth and the internal trochanter confirms our identification of the unusual femoral growth as a pathology and not a muscle attachment site. Although the location on the distal femur and the endochondral ossification of the bone are traits of an osteochondroma, we reject this diagnosis, because in osteochondromas the trabecular bone of the shaft is continuous with the trabecular bone of the growth (Khurana et al. 2002). The presence of the original cortex beneath the protuberance (Fig. 2E,F) suggests that the pathology could be an exostosis formed after damage to the periosteum. Note that at the distal end of the protuberance (Fig. 2G,H), the original cortex is absent. However, this is also the case for the proximal
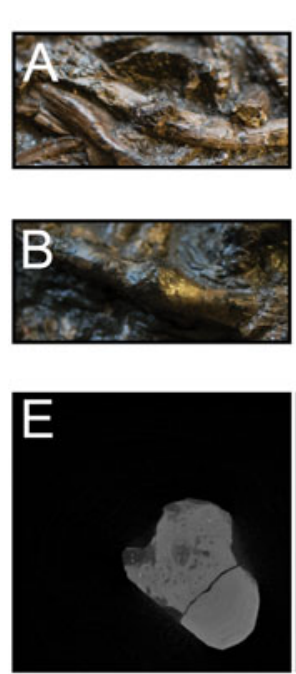
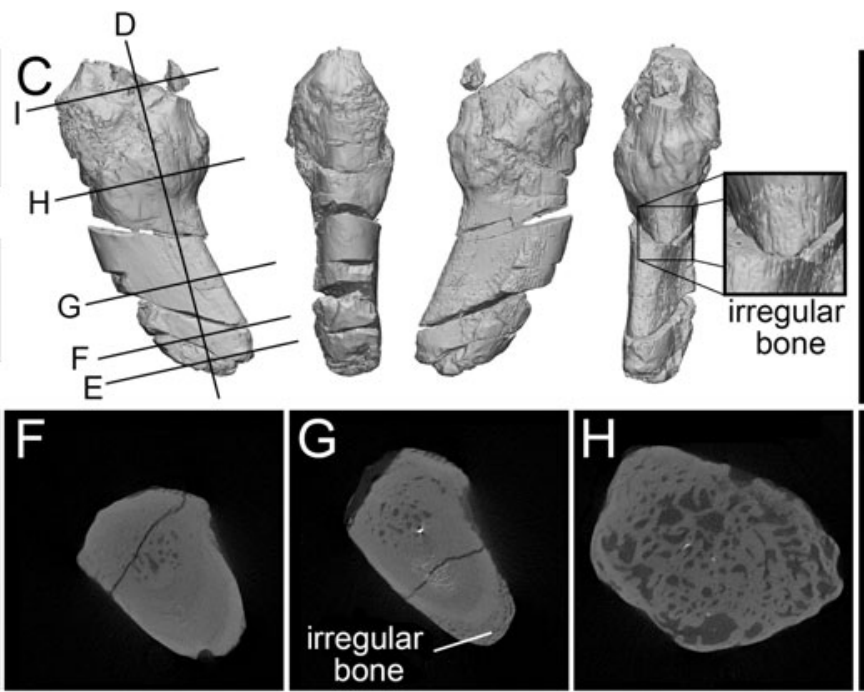
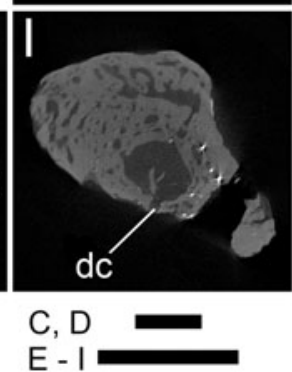

FIGURE 5. Rib pathologies in Crassigyrinus NHMUK VP R10000. A, B, Photos of bony calluses in the healed ribs; C, 3D model of a bony callus on a healed rib fragment [A shows where fragment $\mathrm{C}$ broke off from the slab]; $\mathrm{D}$, long-axis cross section; E, transverse cross section of nonpathological end of fragment; $F$, transverse cross section showing normal structure of the rib shaft; $G$, transverse cross section showing irregular bone formation external to the cortical bone; $H$, transverse cross section showing irregular bone in callus; I, transverse cross section showing sinus with a drainage channel, probably a site of infection. dc, drainage channel. Black lines in C indicate locations of cross sections D-I. Scale bars: $5 \mathrm{~mm}$. 

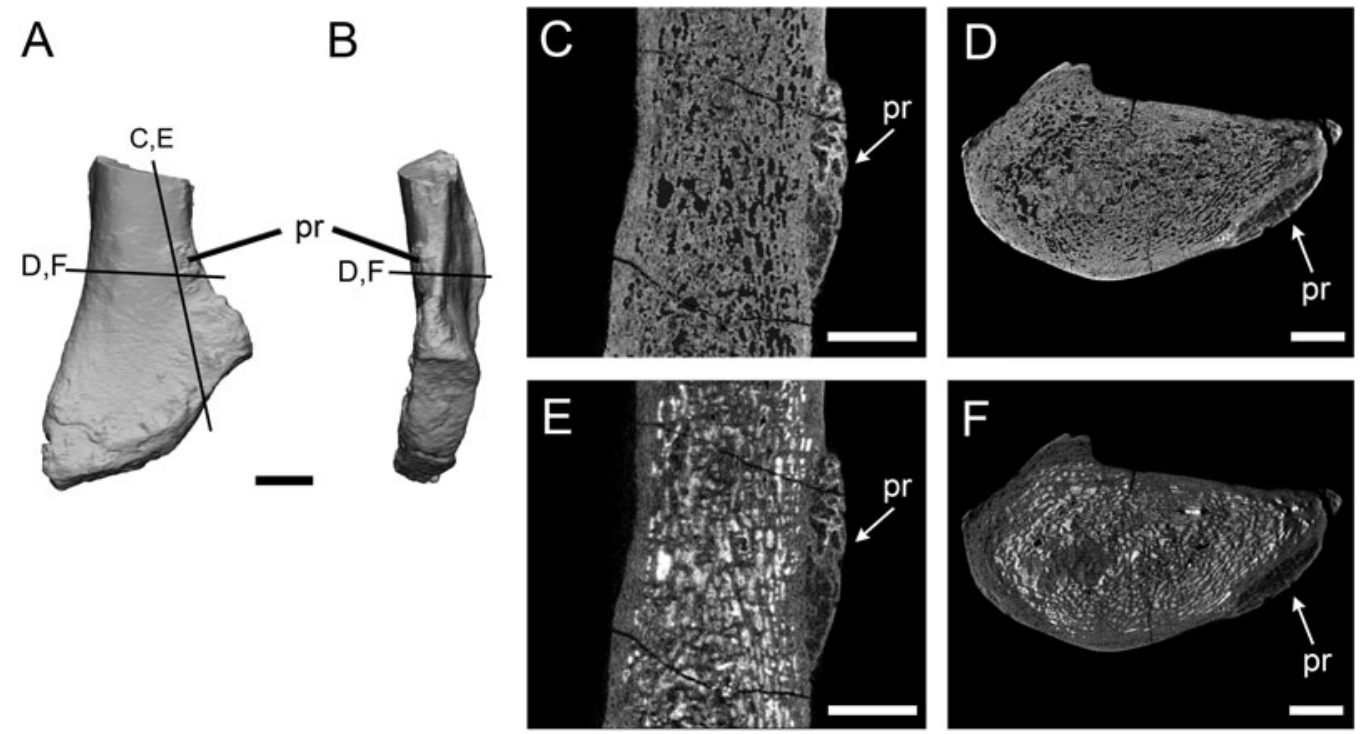

FIGURE 6. Eoherpeton right fibula in lateral (A) and anterior (B) views; protuberance in long axis (C, E) and transverse (D, F) cross sections. The fossil has infill between trabecular spaces in $\mathrm{E}$ and $\mathrm{F}$, this hyperdense matrix in intertrabecular spaces was removed in $C$ and D (see Supplementary Text 3 for image-processing macro information). pr, protuberance. Scale bars: $10 \mathrm{~mm}(\mathrm{~A}, \mathrm{~B}) ; 3 \mathrm{~mm}(\mathrm{C}-\mathrm{F})$.

(nonpathological) end (Fig. 2D). The articular surfaces of the limb elements of the Crassigyrinus fossil are not ossified, the bones probably had cartilaginous joint surfaces, and there may have been taphonomic distortion in this element. Therefore, the extent of the cortex does not provide conclusive evidence to identify the subcategory of bone healing present in this element.

Crassigyrinus tibia.-The protuberance on the Crassigyrinus tibia is on the proximal end of the medial surface (Fig. 3). Like the femur, it is on the flexor surface of the bone, close to the knee joint. The tuberosity on the tibia is triangular, and its surface is rugose, although not as pitted as the femoral protuberance. The internal structure is very similar to that of the femoral protuberance, with cortical bone separating the growth and tibial shaft (Fig. 3C,D). As described for the femur, the presence of the original bone cortex (Fig. 3C) is characteristic of an exostosis. However, this cortex becomes irregular (Fig. 3D), perhaps due to healing of a fracture, although no clear fracture line is visible. Unlike the femoral protuberance, there is no evidence of cortical bone deposition on the external surface of the protuberance. The external and internal morphology leads us to conclude that this growth is evidence of bone healing.

Crassigyrinus metatarsal.-We also discovered a similar lesion on the extensor surface of a Crassigyrinus metatarsal, NMS G 1984.15.2 (Fig. 4A,B). As in the protuberances in the tibia and femur, cortical bone separates the protuberance from the trabecular bone in the shaft (Fig. 4C,D). While we could not compare the femoral and tibial lesions with normal long bones (only one Crassigyrinus femur and one Crassigyrinus tibia have been found), there are six metatarsals attributed to Crassigyrinus (Herbst and Hutchinson 2018). Only one metatarsal has this growth, which supports its identification as a pathology. There is a channel connecting a cavity within the bone protuberance to the outside ("dc" in Fig. 4C), which may represent a draining sinus tract resulting from infection of the bone. Such infection of the cortical bone is called "osteitis" (although osteitis can be caused by osteomyelitis, infection of the bone marrow) (Pineda et al. 2009; Tiemann and Hofmann 2009). The pathology could also be a bony cyst, in which the fluidfilled cavity has started to heal by new bone formation (Jacobs 1955). Infections and cysts can be caused by various factors, such as trauma, but it 
is not possible in this case to narrow down the etiology of this pathology. Regardless, all of these possibilities indicate net changes in bone geometry as a healing response.

Comparison with Ossinodus.-A strikingly similar pathology to those in the Crassigyrinus hindlimb bones, in terms of external and internal structure, was described on the proximal right radius of Ossinodus QMF 37451 (Queensland Museum, Brisbane), an early tetrapod from the mid-Viséan of Australia (Warren and Ptasznik 2002). The Ossinodus radial pathology is especially similar to that of the Crassigyrinus tibia, because in both cases the pathology is at the proximal end of the zeugopod, near the elbow and knee joints, respectively (Supplementary Fig. 1). The Ossinodus pathology is the oldest known evidence of bone healing in a tetrapod. Based on the pathology and other features of the internal bone structure, Bishop et al. (2015) inferred that Ossinodus moved on land to some degree. The presence of similar pathologies in the aquatic Crassigyrinus and in the well-ossified and more terrestrial Eoherpeton (see "Eoherpeton" section) demonstrates that early tetrapods with a variety of locomotor modes experienced such pathologies.

Crassigyrinus ribs.- The Crassigyrinus ribs exhibit the only pathology in Crassigyrinus that has been previously described. The NHMUK VP R10000 specimen shows bony callus formation, which is evidence of a healed fracture, in four ribs (Panchen 1985). The surfaces of these calluses are rugose, like the surfaces of the hindlimb pathologies (Fig. 5A-C). Unlike in the hindlimb, the rib pathologies involve the entire cross section of the rib at the site of the callus. Whereas the normal bone structure in the rib shaft is very dense (Fig. 5F), the callus is composed of loose unorganized trabecular bone and lacks cortical bone (Fig. 5H). This corroborates Panchen's interpretation of these calluses as evidence of healed rib fractures. The XMT scans also revealed subperiosteal primary bone formation, which may have formed in reaction to the nearby fracture or as a result of a separate subcritical fracture event (Fig. 5G). There is also a large sinus in the bone with a channel leading to the outside, which might be a site of infection with a drainage channel (Fig. 5I).
Eoherpeton.-The right fibula of Eoherpeton has a protuberance similar to the Crassigyrinus lesions, in that it is a raised, button-shaped growth on the anterior margin of the lateral side of the distal fibula (Fig. 6). Smithson (1985) reported this feature and noted that is not present in Archeria, whose overall fibular morphology is similar to that of Eoherpeton. We identified this feature as a possible pathology, and therefore investigated the internal structure. Our XMT imaging supports this interpretation. The bone is much less dense in the presumably pathological area compared with the ridge on the posterior edge of the medial side. The latter ridge is probably part of the normal morphology of the fibula, because it is also described in Archeria (Smithson 1985), as well as most other early tetrapods, and is an osteological correlate of the origin of the flexor accessorius lateralis (Molnar et al. 2018). The difference in density between the ridge and the growth is not just a taphonomic artifact of the presence of infill (white in Fig. 6E,F) versus no infill (Fig. 6C,D). Furthermore, the protuberance is not found on the left fibula associated with Eoherpeton (see Supplementary Text 2 for specimen info).

Bone Healing, Remodeling, and Regeneration Extinct Taxa.-

Stem tetrapods.- The earliest known case of bone healing in a tetrapod is in a radius of Ossinodus from the mid-Viséan ( 333 Ma) of Australia (Warren and Ptasznik 2002; Bishop et al. 2015). This pathology has a similar appearance to the Crassigyrinus tibial protuberance. Godfrey (1988) described fracture calluses in the ribs of a tetrapod from the late Viséan of West Virginia, and attributed these ribs to Crassigyrinus. There is not enough evidence to support this taxonomic referral, but nevertheless it is another case of fractured and healed ribs in a tetrapod from the Carboniferous. Cases of bone healing are even more common after the Carboniferous and have been described for various taxa. We end our synthesis of bone healing data at the Carboniferous for fossil tetrapods, because subsequent cases of healing do not add any new information on ancestral patterns. 
Other sarcopterygians (lobe-finned fish): porolepiforms, lungfish, Rhizodontida.-The oldest known instance of bone repair in Sarcoptergygii is fracture repair with callus formation in response to bite injury on a scale of the porolepiform Glyptolepis from the Eifelian stage, Middle Devonian. A scale that probably belongs to the porolepiform Holoptychius also displays healed bone (Lebedev et al. 2009). The first evidence of endoskeletal bone healing is in the Carboniferous, and there are many examples in non-tetrapod sarcopterygians of this period. Several healed ribs (which are endochondral bone) are reported in lungfish from Scotland (Sharp and Clack 2013), Kansas (Rothschild and Martin 2006), and England (Barkas 1873). The healed bone at the sites of these fractures appears very similar to that in the healed Crassigyrinus ribs, forming a callus on the rib shaft. There are also two fractured lepidotrichia (fin rays composed of dermal bone) with callus formation (indicating a healing response) in the rhizodontid (extinct tetrapodomorph fish) Barameda from the early Carboniferous of Australia (Garvey et al. 2005). We found no studies with evidence of bone healing in fossil Actinistia (coelacanths).

Actinopterygians (ray-finned fish).-Evidence of bone healing is rarely reported in the fossil record of actinopterygians. However, there are several cases from the Eocene Messel pits. Fracture repair, identified by callus formation, was present in the bony caudal fin rays of Cyclurus (Amiidae), Amphiperca (Serranidae), Paleoperca (Serranidae), and Rhenaoperca (Micklich and Mentges 2012).

Placoderms.-There is evidence of healing and remodeling around a trauma-induced lesion in the dorsal plate (composed of dermal bone) of the placoderm Dunkleosteus from the Givetian stage, Middle Devonian (Capasso et al. 1996). The outer layer (which exhibits the most extensive healing and remodeling) was described as "dentine-like." However, we determine the identity of the healed tissue to be bone, not dentine. The study noted the presence of bone cells and lamellae in this layer, and histological analysis of Dunkleosteus showed no evidence of dentine (Giles et al. 2013). Lebedev et al. (2009) reported several instances of bone healing in Late Devonian taxa, as follows. The placoderm Plourdosteus shows healing of the compact bone over the spongy bone at the injury margins. Another placoderm, Bothriolepis, exhibits lesions and healing (including callus formation) on both the ventrolateral plate and pectoral fin (in different individuals). Secondary osteons in another Bothriolepis species also indicate remodeling capacity (Downs and Donoghue 2009). Indeed, remodeling during growth is often found in various placoderms, including Dunkleosteus (Giles et al. 2013).

Osteostracans.-Although healing has not been reported in osteostracans, resorption of bone has been observed in Tremataspis (Denison 1952).

\section{Extant Taxa.-}

Sarcopterygians (including Tetrapoda).Fracture repair of endochondral bones is similar across extant tetrapods. Axolotls (Ambystoma), which are capable of regeneration, repair fractures in the same manner as mammals, and in tetrapods (regardless of regeneration capacity) there is a critical gap size beyond which a fracture cannot heal (Hutchison et al. 2007). Fracture repair of dermal bones differs between extant tetrapod taxa. Mammals and birds heal dermal bones by forming a cartilaginous callus in a process called secondary chondrogenesis (Irwin and Ferguson 1986). Secondary chondrogenesis is the formation of cartilage from the periostea of dermal bones after intramembranous ossification has occurred (Hall 2005). Salamanders and newts do not form cartilage during the healing of dermal bones (Goss and Stagg 1958; Hall and Hanken 1985). There is no evidence of secondary chondrogenesis in snakes or lizards (Irwin and Ferguson 1986). No mechanistic studies of fracture repair, to our knowledge, have been conducted on crocodiles or turtles. In dermal bone fractures without secondary chondrogenesis, a callus still forms, but it is composed of fibrous tissue (Irwin and Ferguson 1986). The African lungfish Protopterus heals dermal bone in its lower jaw by forming a fracture callus, and bone remodeling is associated with the injury (Kemp 2001). Bone healing in extant coelacanths has not been described. Fracture repair in extant tetrapods is usually followed by remodeling (see "Introduction"). In mammalian endochondral 
fracture repair, there are two stages of osteoclast activity: resorption of calcified cartilage after soft callus formation and remodeling of bone in the hard callus (Gerstenfeld et al. 2003). In calcified cartilage resorption, osteoclasts are sometimes referred to as "chondroclasts," due to the substrate on which they are working. Chondroclasts and osteoclasts appear to be the same cell type based on shared features and regulatory mechanisms and osteoclasts' capacity for resorbing mineralized cartilage (Helfrich 2003; Włodarski et al. 2014).

Some extant sarcopterygians can repair damaged skeletal tissue not only through fracture repair but also through regeneration. The fracture repair process differs from the limb regeneration process. Limb regeneration involves cell dedifferentiation, and the formation of a blastema, whereas fracture repair does not. Axolotls can fully regenerate amputated limbs (Hutchison et al. 2007). The frog Xenopus forms a blastema but only grows a cartilaginous spike in response to amputation (Egawa et al. 2014). Lizards can regenerate their tail, but a cartilaginous rod replaces bony vertebrae (Jacyniak et al. 2017). The lungfish Protopterus can regenerate endochondral and dermal bone in its fins and tail, and the regeneration mechanism is similar to that of urodeles (Conant 1970).

Bone remodeling is widespread in tetrapods, enabling growth, repair, and mineral homeostasis (Witten and Huysseune 2009; Doherty et al. 2015). Although remodeling is much reduced in small birds and mammals (Currey et al. 2017), remodeling is still possible in these taxa; for example, it can be induced in rats by increased loading (Bentolila et al. 1998). Extant lungfish (Neoceratodus) show evidence of bone resorption in and below their dental plates during normal growth (Kemp 2001, 2002a).

Actinopterygians.--Regeneration in actinopterygians proceeds like urodele regeneration, involving a blastema formed of dedifferentiated cells (Kemp and Park 1970; Knopf et al. 2011; Sousa et al. 2011). Zebrafish (Danio, osteocyte-bearing teleosts) can regenerate their caudal and pectoral fins in response to fin ray amputation (Akimenko et al. 1995; Sousa et al. 2011, 2012). They can also heal bone fractures, but unlike in sarcopterygians, their fracture repair also involves tissue dedifferentiation; a blastema forms in both crush fractures (Sousa et al. 2012) and normal fractures of fin rays (lepidotrichia, which are dermal bones), as well as in fractures of skull bones (Geurtzen et al. 2014). In crush fractures in zebrafish, the bone repair process takes longer than in amputation regeneration (Sousa et al. 2012). In medaka (Oryzias), fin regeneration also proceeds more quickly than fracture repair (Takeyama et al. 2014). No secondary cartilage forms during the healing of dermal bones in fish (Irwin and Ferguson 1986).

Glass knifefish (Eigenmannia) can regenerate endochondral bone in their tail. Amputated vertebrae do not reform, but are replaced by a long rod with the same histological structure as the vertebrae (Kirschbaum and Meunier 1981). Polypterus (bichirs) regenerate their pectoral fins (composed of both endoskeletal and dermal bones) by forming a blastema, similar to amphibian regeneration. These studies demonstrated that actinopterygian fins can regenerate in response to amputation of the endoskeleton (endochondral fin bases), instead of regeneration being restricted to only the exoskeleton (composed of the fin rays; dermal bone) (contrary to Akimenko and Smith 2007). Gene expression is also similar in Polypterus, lungfish, and salamander regeneration, suggesting a common evolutionary origin of regeneration in these taxa ( $\mathrm{Lu}$ et al. 2019). Tilapia can regenerate lepidotrichia of the anal fin, and these regenerated structures segment and branch during growth, as do lepidotrichia formed during normal growth (Kemp and Park 1970).

In the zebrafish crush-injury model, a soft callus formed from an epithelial thickening, and bone deposition at the crush site was rounded, which is morphologically similar to bony callus formation in tetrapod fracture repair. Gene expression indicated that in the crush model, repair was prolonged and probably involved remodeling (Sousa et al. 2012). Similarly, in zebrafish fin ray fracture, a callus (composed of collagen fibers) formed and then mineralized to form bony callus. The subsequent remodeling appears similar to 
remodeling of a fracture callus in humans (Geurtzen et al. 2014).

Moss (1962) investigated fracture repair of dermal bones (opercular and lower jaw) in freshwater fish, the osteocytic Tilapia and the anosteocytic Carassius. Both species formed fracture calluses in the lower jaw, although Carassius appeared to show earlier and more abundant bone formation in the fracture callus. Carassius was able to calcify and ossify the fracture callus even in acalcemic water, unlike Tilapia. Moss (1962) also observed fracture callus formation in the anosteocytic marine fish Fundulus, but the fracture callus was smaller than in the freshwater fish examined and was mostly cartilaginous, with some calcification and some bone formation. Hematoma formation was not as pronounced in the fracture repair of these teleost fishes as in tetrapods (Moss 1962); in mice, inflammation and hematoma formation plays an important role in the healing process (Bahney et al. 2018). Although these cartilage calluses in fish formed in dermal bone (which develops through intramembranous rather than endochondral ossification), they formed only upon damage to primary cartilage; therefore, the jaw callus cartilage is not "secondary cartilage." The opercula did not form cartilaginous calluses and did not heal well (Moss 1962).

The anosteocytic medaka (Oryzias) can heal the caudal lepidotrichia, forming a fracture callus that ossifies and remodels (Takeyama et al. 2014). Osteoclasts are first induced to resorb bone fragments and then to remodel the callus (Takeyama et al. 2014). Remodeling in response to increased load has been reported in the opercula of tilapia, Oreochromis (Atkins et al. 2015). In the anosteocytic amphibious fish Kryptolebias, gravitational loading increased gill arch stiffness, and proteomic analysis showed that the mechanisms were similar to those of tetrapod bone remodeling (Turko et al. 2017).

Chondrichthyans.-The skeleton of extant chondrichthyans contains only small amounts of bone, for example, in the neural arches of dogfish (Scyliorhinus). This bone shows evidence of resorption by mononucleated cells, and mono- and multinucleated cells can resorb bone implanted in the dorsal musculature
(Peignoux-Deville et al. 1982, 1989; Bordat 1987). No healing of this bone or chondrichthyan cartilage has been reported.

\section{Aspidin Healing and Remodeling}

Extinct Taxa.-

Heterostracans.-Aspidin healing has been found in Psammolepis (Paleontological Museum of St. Petersburg University 46-1), which shows a projection with both spongy and lamellar aspidin, the former of which is much denser than the spongy layer found in uninjured dorsal plates (Lebedev et al. 2009). Resorption of aspidin and deposition of new aspidin has been reported in Ganosteus (Tarlo 1964; Halstead 1969, 1973). Furthermore, growth series of Pteraspis reveal that remodeling must have occurred during fusion of head and trunk plates; there is a seamless continuation in the cancellous aspidin between some adult trunk plates, whereas juvenile plates are separate and rimmed with spongy aspidin (Halstead 1969). There is also evidence of remodeling in Tesseraspis, Corvaspis, Phialaspis, Amphiaspis, and Psammosteus (Keating et al. 2015).

Extant Taxa.-Aspidin is not found in any extant taxa. Most teleosts have acellular bone (see section on Bone Healing, Remodeling, and Regeneration: Extant Taxa), but this acellularity is a derived evolutionary trait (Meunier and Huysseune 1991; Moss 1961).

\section{Dentine Healing and Remodeling \\ Extinct Taxa.-}

Sarcopterygians (lobe-finned fish): porolepiforms and lungfish.- The porolepiform Glyptolepis from the Eifelian stage of the Middle Devonian shows denticle healing during fracture repair of a bite injury on a scale (Lebedev et al. 2009). The lungfish Mioceratodus from the mid-Tertiary shows a lesion without dentine healing or remodeling (although normal tissue growth was observed near the lesion). Kemp (2001) concluded that fossil lungfish were unable to remodel or repair dentine.

Chondrichthyans and placoderms.-The acanthodian Doliodus (see "Materials and Methods" for information about chondrichthyan affinity) from the Early Devonian shows dentine healing of fin spine fractures without visible resorption (Burrow et al. 2017). 
The Middle Devonian arthrodire placoderms Eastmanosteus and Actinolepis show irregular tubercle formation in response to injury on their dermal plates (Lebedev et al. 2009).

Heterostracans and osteostracans.-The oldest clear case of cell-mediated healing of a mineralized tissue in a vertebrate is dentine healing on the dorsal shield of the heterostracan Larnovaspis from the Lochkovian stage, Early Devonian (Lebedev et al. 2009). Johanson et al. (2013) found the majority of healing of a Psammolepis injury to be dentine infilling (rather than aspidin healing), and argued that such dentine infilling to repair bone evolved before bone repair. However, aspidin also healed in heterostracans (see "Aspidin Healing and Remodeling" section). Another specimen of Psammolepis shows healing of dentine by formation of unusual, small dentine tubercles (in addition to the aspidin healing in the same specimen, described in "Aspidin Healing and Remodeling") (Lebedev et al. 2009). The Middle Devonian psammosteid Pycnosteus grew secondary dentine tubercles on a healing scale (Lebedev et al. 2009). Another Psammosteus species shows healing of a fracture via dentine tubercle deposition (Halstead 1969). Keating et al. (2018) reported remodeling in the superficial layer (composed on dentine) of the dorsal shield of the heterostracan Psammosteus. Resorption of dentine tubercles followed by subsequent growth of new tubercles has been observed in the heterostracan Ganosteus from the Middle Devonian (Halstead 1973). Secondary dentine formation in a heterostracan resembled that of secondary dentine formed in human teeth in response to caries, which indicates a conserved healing mechanism (Tarlo 1964; Halstead 1973).

Lebedev et al. (2009) described several other cases of healing in heterostracans, for example, in the dorsal plates of several Psammolepis species from the Givetian, Middle Devonian. Both injuries damaged the aspidin layer in the shield, which subsequently healed, but the identification of the healed tissue was not reported; it could be either aspidin or dentine. Denison (1952) reported remodeling of dentine tubercles (resorption and subsequent replacement) in the osteostracan Cephalaspis.

\section{Extant Taxa.-}

Tetrapods.-Dentine in humans can repair in response to insults such as disease, chemicals, or trauma by depositing tertiary dentine; this dentine is called either reparative or reactive dentine based on the cell history of the odontoblasts involved in its secretion (Smith et al. 1995). Molecules involved in dentinogenesis during development are re-expressed during tooth repair (Mitsiadis and Rahiotis 2004). Remodeling of dentine in human teeth occurs both during development (via formation of secondary dentine) and in pathological reactions (Mitsiadis et al. 2008).

Lungfish.-Dentine in the extant lungfish Neoceratodus is unable to remodel during growth. Partial dental ridge fracture in Protopterus showed that the damaged dentine was not remodeled or repaired, although new dentine grew near the fracture (Kemp 2001, 2002a).

\section{Conodont Mineralized Tissues}

The phosphate-based dental elements of conodonts from the Silurian were also capable of healing fractures and scratches (Shirley et al. 2018). This repair was systematic, but a pathological specimen is also known, in which abnormal growth and/or repair led to abnormal morphology. No remodeling of the damaged areas occurred.

\section{Phylogenetic Synthesis}

Here we consider the previously discussed observations in a phylogenetic context to reconstruct how bone healing evolved. No major variation in bone healing patterns of dermal and endochondral bone is evident in extinct or extant tetrapods (Fig. 7), except for secondary chondrogenesis in the healing of dermal bone in birds and mammals. However, the absence of secondary chondrogenesis during healing of dermal bones in nonavian reptiles, amphibians, and several teleost fish, and differences in the secondary cartilage of birds and mammals, indicate that this process evolved convergently in birds and mammals (Irwin and Ferguson 1986; Hall 2005). Secondary cartilage also forms during the development of the maxilla, dentary, and cleithrum (after intramembranous ossification) in the teleost Poecilia sphenops (Benjamin 1989). This indicates a third independent origin of secondary chondrogenesis 


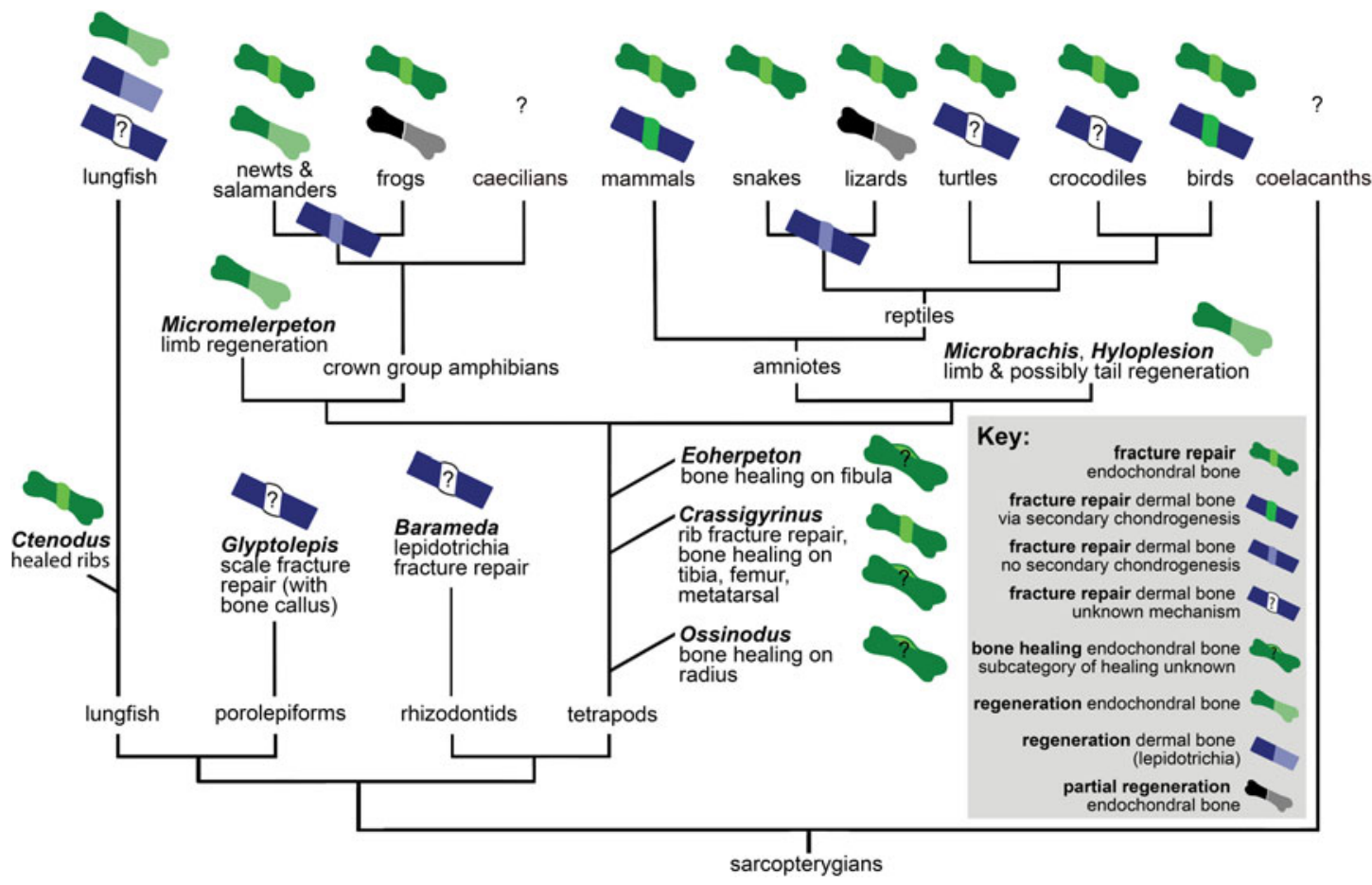

FIGURE 7. Distribution of bone healing and regeneration in sarcopterygians, showing key data discussed in "Bone Healing, Remodeling, and Regeneration," which establish that these fundamental healing mechanisms are ancestral for the clade. See "Materials and Methods" for detail on phylogeny.

(Hall 2005). However, to our knowledge, secondary chondrogenesis during dermal fracture repair has only been reported in birds and mammals, and its absence has been reported in other teleost fish such as Fundulus (Moss 1962). It would be interesting to investigate whether dermal bone fracture repair in Peocilia also involves secondary chondrogenesis.

Fossil porolepiform and rhizodontid fish show evidence of dermal bone healing, and fossil lungfish show endochondral bone healing with calluses like those found in fracture repair of extinct and extant tetrapods. Extant lungfish form and remodel a callus in response to dermal bone injury. Therefore, we infer that the same fundamental mechanisms of healing of dermal and endochondral bone were ancestral not only for tetrapods but for Sarcopterygii.

There are interesting differences in sarcopterygian and actinopterygian fracture repair pathways. For example, zebrafish dedifferentiate cells to form a blastema during both fracture repair and regeneration, but tetrapods only dedifferentiate cells during regeneration. Additionally, inflammation pathways play a larger role in fracture repair of tetrapods than in fracture repair of osteocytic freshwater and anosteocytic marine and freshwater teleost fish. It is unclear whether this difference in pathways indicates a convergent evolution of specific healing processes in actinopterygian and sarcopterygian bone or modifications to an ancestral healing pathway. However, several other similarities of the fracture repair pathways suggest the latter. The formation of a fracture callus occurs in sarcopterygians as well as actinopterygians, and in most cases this callus is subsequently remodeled. In both medaka (Oryzias) lepidotrichial fracture and mammalian long bone fractures, two stages of osteoclast activity have been reported. The second stage of osteoclast activity remodels the bony callus in both groups, and blocking the induction of these osteoclasts prevents callus remodeling (Schindeler et al. 2008; Takeyama et al. 2014).

The presence of a cartilaginous versus a fibrous callus stage varies within actinopterygians and sarcopterygians, depending on 


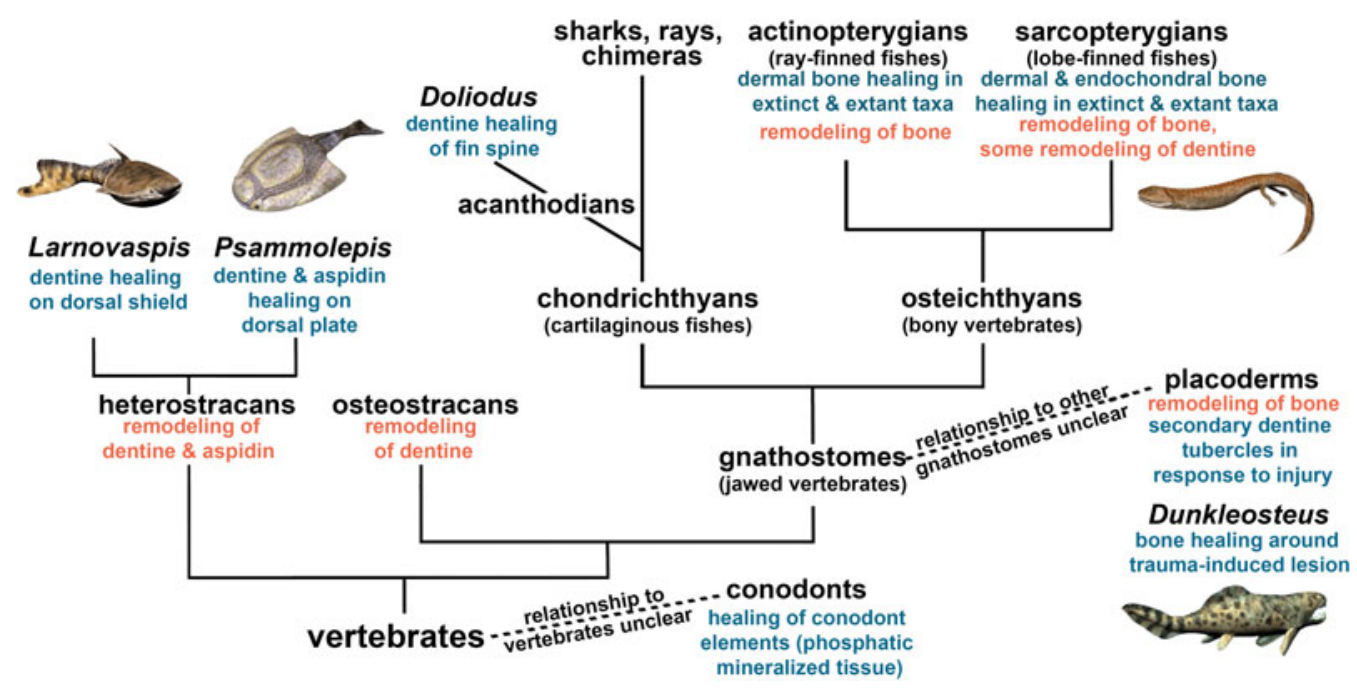

FIGURE 8. Cell-mediated healing and remodeling of mineralized tissue in vertebrates, indicating the ancestral nature of skeletal repair capacity. Certain species have been added as examples, but the fossil record extends beyond these examples. See "Materials and Methods" for detail on phylogeny. Artwork by Nobu Tamura, CC BY-SA 3.0 license, http://spinops. blogspot.com, https://creativecommons.org/licenses/by-sa/3.0.

bone type and the specific taxon. However, in all taxa and both dermal and endochondral bones, fracture of the bone at the organ level results in callus formation. Bone healing evolved early in vertebrates, as is evident in heterostracans (aspidin healing) and placoderms (cellular bone healing). A recent evolutionary analysis suggested that aspidin was the ancestral bone type, with cellular bone evolving from it at least two times in vertebrate evolution (Keating et al. 2018). Cellular bone first evolved in osteostracans, and its presence in placoderms, acanthodians, and osteichthyans suggests that cellular bone is a synapomorphy of gnathostomes and osteostracans (Brazeau and Friedman 2014; Davesne et al. 2019). Because a healing mechanism is found in both aspidin and cellular bone, and cellular bone evolved from aspidin, it is most parsimonious that the healing mechanism evolved in early vertebrate bone (regardless of its cellularity). This, taken together with the widespread distribution of bone healing in extant vertebrates, leads us to conclude that dermal bone healing evolved early on in vertebrates, rather than convergently evolving in all these taxa.

Based on evidence from fossil and extant animals, bone regeneration in the appendages and tail is also ancestral for sarcopterygians and perhaps all osteichthyans (Fröbisch et al. 2015; Nogueira et al. 2016; van der Vos et al. 2018; Lu et al. 2019). However, there does not appear to be a direct link between healing and regeneration processes; regeneration is not an exaggerated form of bone healing, as evidenced by differences in pathways and the inability to heal a fracture gap in both regenerating and nonregenerating taxa (Roy and Lévesque 2006).

We then considered how the healing of mineralized tissues evolved within vertebrates. The evolutionary homologies of these tissues remain contentious, but our synthesis (Fig. 8) infers that the capacity for cell-mediated repair of skeletal tissues was ancestral for vertebrates. Bone remodeling is widespread in extinct and extant vertebrates, and bone remodeling mechanisms are similar in extant tetrapods and anosteocytic fish (Turko et al. 2017), which supports our interpretation that bone remodeling is also ancestral for vertebrates. Furthermore, we found that remodeling co-occurred with healing in bone (including aspidin) and dentine in the same taxa (heterostracans, placoderms) early on in vertebrate evolution. Not only are the same taxa capable of remodeling and healing, but remodeling has been reported as a part of the healing process, for example, in Dunkleosteus (Capasso 
et al. 1996). Although healing has not been reported for osteostracans, they were able to resorb bone, and based on their phylogenetic placement, we conclude that the absence of healing evidence may be due to lack of preservation. Conodonts (an outgroup to vertebrates) were able to heal their dental elements, but this healing does not show evidence of remodeling (Shirley et al. 2018). The convergent evolution of mineralized tissues in conodonts provides an example of a healing mechanism with formation only.

\section{Discussion}

The paleopathologies we described in Eoherpeton and Crassigyrinus are some of the earliest reported cases of bone healing for tetrapods. Our evolutionary synthesis led us to discover that, like regeneration, bone healing is ancestral for tetrapods and probably for sarcopterygians. However, the pathways of these two repair processes (bone healing and regeneration) are distinct, and most sarcopterygians have lost regeneration capacities, whereas bone healing is ubiquitous among all sarcopterygians studied. Furthermore, our phylogenetic synthesis of vertebrates suggests that healing is ancestral for vertebrate bone and other early vertebrate mineralized tissues. Bone, aspidin (acellular bone), and dentine were all able to undergo both healing and remodeling early in vertebrate evolution. This evidence led us to infer that there is an evolutionary and mechanistic link between healing and remodeling capacity.

It is interesting to note that, although both regeneration and repair could be advantageous to survival, most extant sarcopterygians cannot regenerate, but all sarcopterygians seem to have retained the ability to heal bone. There are several hypotheses about the evolution, maintenance, and loss of regeneration. For example, some taxa might have reduced likelihood of structure loss, and therefore regeneration might have been lost because it was neutral or costly to maintain (Bely and Nyberg 2010). Alibardi (2018) suggested that loss of regeneration is linked to the loss of metamorphosis during development. However, this correlation is not supported by the fossil record of tetrapods. While regeneration was ancestral for early tetrapods (Fröbisch et al. 2015; Nogueira et al. 2016; van der Vos et al. 2018; Lu et al. 2019), anatomical analysis of growth series of early tetrapods suggests that lissamphibianlike water to land metamorphosis was not ancestral for early tetrapods, and evolved in a lissamphiban ancestor (Schoch 2001). Branchiosaurids (temnospondyls) from the late Carboniferous show the earliest reported evidence of lissamphibian-like metamorphosis (Schoch and Fröbisch 2006). On the other hand, although no fossil evidence exists, it is possible that early tetrapods metamorphosed in water (Schoch 2001). Alibardi's (2018) argument is that genetic pathways important for metamorphosis also enable regeneration, and if metamorphosis is lost, then these genes are also lost, preventing regeneration. If a fish-like metamorphosis between larval and adult stages is discovered in early tetrapods, this would reconcile Alibardi's (2018) argument of the link between metamorphosis and regeneration with fossil evidence (Schoch 2001; Schoch and Fröbisch 2006) that lissamphibian-like metamorphosis evolved after regeneration evolved. Another hypothesis concerns the role of developmental pathways in regeneration; in amniotes, development is more dependent on transient structures such as somites, and as their existence is limited to early embryo stages, this might prevent development of new structures during the regeneration process. Amphibians, on the other hand, develop limbs in a more "self-organized" manner (Galis et al. 2003).

There does not seem to be a link between regeneration and healing, but can the fossil record reveal anything more about whether remodeling and healing are linked? Mineralized tissues can heal by formation only (i.e., without resorption), but healing is usually followed by remodeling in extant vertebrates. In bone (including aspidin) and dentine, there is evidence of both remodeling and healing emerging in the same taxa early on in vertebrate evolution. Ashhurst (2004) suggested that bone's capacity to remodel and integrate old and new matrix might explain why bone can heal well and shark cartilage (which does not remodel) cannot. The connection between frequent remodeling and full healing ability appears to exist not only for bone and cartilage, 
but for other vertebrate skeletal tissues. Our phylogenetic analysis reveals that dentine and aspidin (acellular bone) both have a long evolutionary history of remodeling and healing capabilities (evident in early fossil vertebrates), and enamel has neither.

Remodeling did not necessarily evolve as a part of the healing pathway. Indeed, there has been much discussion about whether bone remodeling initially evolved for homeostasis, growth, and / or removal of microdamage (Martin 2003; Doherty et al. 2015; Currey et al. 2017). It is debated whether heterostracan dentine remodeling (via tubercle turnover) evolved as a healing or growth mechanism (Halstead 1969). It is difficult to test why remodeling evolved, and there may have been a combination of selective pressures. Regardless, our evolutionary synthesis reveals that there is a link between healing and remodeling processes.

Future studies comparing cell interactions in bone, dentine, cartilage, and enamel may give insight into the specific tissue properties that enable active remodeling and healing. Perhaps exceptions in a tissue's ability to heal and remodel can be traced to differences in the cell and matrix interactions in the tissues of these specific taxa. Such exceptions include the increased capacity of healing of specific types of cartilage, such as the auricular cartilage in rabbits (Hall 2015), and the inability of lungfish to remodel or heal their dental plates. Indeed, lungfish tooth plates differ from teeth of most other vertebrates, because they continuously grow and have denteons, so perhaps there is some physiological link between these two traits and the inability to remodel or repair. On the other hand, lungfish might have lost the ability to remodel and heal dentine because this trait was no longer adaptive, and continuous growth enabled sufficient restoration of function after injury. In any case, the inability of lungfish to remodel and heal dentine further supports a link between these processes.

From an evolutionary standpoint, both healing and remodeling have metabolic costs. Remodeling also has a mechanical cost, because there is a period of structural weakness when resorption has occurred but deposition of new bone has not yet re-established bone mass and strength (Felder et al. 2017). However, both remodeling and healing evolved early on and have been retained in extant animals, suggesting that the benefits of these two processes outweigh the metabolic and mechanical costs. Healing is advantageous, because it restores the strength of bone through modeling. Injuries and insults from biological (intraspecific, predator-prey, disease) and environmental interactions (fatigue damage, trauma) would prove detrimental to extinct and extant vertebrates without healing. Healing through blastic formation only is possible; such a repair mechanism was present in mineralized tissues of conodonts (Shirley et al. 2018). However, it is only through remodeling that healing without mass gain (and associated metabolic costs) is possible (Martin 2003). Although the ultimate evolutionary cause (sensu Mayr 1961) for the evolution of remodeling remains unclear, our results elucidate the timing and consequences of the evolution of remodeling in relation to the evolution of healing.

\section{Conclusions}

Both the aquatic Crassigyrinus and the more terrestrial Eoherpeton were able to heal bone, showing healing in response to injury or disease in early tetrapods with a range of locomotor capacities and habitats. Bone healing is found in extant and extinct Osteichthyes, as well as placoderms (early gnathostome vertebrates). Aspidin (acellular bone) healing is found in heterostracans (early agnathan vertebrates). Dentine healing is also found in heterostracans and placoderms. Based on our analysis of extinct and extant taxa, we conclude that ancestral vertebrate skeletons were able to heal after insult and injury. Our analysis reveals an early, concurrent evolutionary origin of both healing and remodeling of dentine and bone (including aspidin). This shows that early vertebrates were not only capable of healing but could recover fully by reaping the benefits of subsequent remodeling (which restores mature bone tissue structure and strength) in these tissues.

\section{Acknowledgments}

We thank S. Chapman (Natural History Museum London) and S. Walsh (National 
Museums Scotland) for specimen access, K. Smithson (University Museum of Zoology, Cambridge) for scanning of specimens, P. Bishop for discussions, and the Queensland Museum, Brisbane, and P. Bishop for Ossinodus photographs. We thank two anonymous reviewers for their constructive feedback, which greatly improved this article. We thank the Natural Environment Research Council for supportive funding under grant numbers NE/K004751/1 (J.R.H.) and NE/J022713/1 (J.A.C., T.R.S.) and the Wellcome Trust for funding under grant number 093234 (X-ray microtomography scanner at the Royal Veterinary College). Artwork by N. Tamura, CC BY-SA 3.0 license, http://spinops.blogspot. com, https://creativecommons.org/licenses/ by-sa/3.0.

\section{Literature Cited}

Akimenko, M. A., S. L. Johnson, M. Westerfield, and M. Ekker. 1995. Differential induction of four Msx homeobox genes during fin development and regeneration in zebrafish. Development 121:347-357.

Akimenko, M., M. Marí-Beffa, J. Becerra, and J. Géraudie. 2003. Old questions, new tools, and some answers to the mystery of fin regeneration. Developmental Dynamics 226:190-201.

Akimenko, M., and A. Smith. 2007. Paired fin repair and regeneration. Pp. 152-162 in B. K. Hall, ed. Fins into limbs: evolution, development and transformation. University of Chicago Press, Chicago.

Alibardi, L. 2018. Organ regeneration evolved in fish and amphibians in relation to metamorphosis: speculations on a postembryonic developmental process lost in amniotes after the water to land transition. Annals of Anatomy/Anatomischer Anzeiger 222:114-119.

Anné, J., N. P. Edwards, R. A. Wogelius, A. R. Tumarkin-Deratzian, W. I. Sellers, A. van Veelen, U. Bergmann, D. Sokaras, R. Alonso-Mori, K. Ignatyev, V. M. Egerton, P. L. Manning. 2014. Synchrotron imaging reveals bone healing and remodelling strategies in extinct and extant vertebrates. Journal of the Royal Society Interface 11:20140277.

Ashhurst, D. E. 2004. The cartilaginous skeleton of an elasmobranch fish does not heal. Matrix Biology 23:15-22.

Atkins, A., J. Milgram, S. Weiner, and R. Shahar. 2015. The response of anosteocytic bone to controlled loading. Journal of Experimental Biology 218:3559-3569.

Bahney, C. S., R. L. Zondervan, P. Allison, A. Theologis, J. Ashley, J. Ahn, T. Miclau, R. Marcucio, and K. D. Hankenson. 2018.

The cellular biology of fracture healing. Journal of Orthopaedic Research 37:35-50.

Barkas, T. P. 1873. Illustrated guide to the fish, amphibian, reptilian, and supposed mammalian remains of the Northumberland Carboniferous Strata. London: W.M. Hutchings.

Bely, A. E., and K.G. Nyberg. 2010. Evolution of animal regeneration: re-emergence of a field. Trends in Ecology and Evolution 25:161-170.

Benjamin, M. 1989. The development of hyaline-cell cartilage in the head of the black molly, Poecilia sphenops. Evidence for secondary cartilage in a teleost. Journal of Anatomy 164:145-154.
Bentolila, V., T. M. Boyce, D. P. Fyhrie, R. Drumb, T. M. Skerry, and M. B. Schaffler. 1998. Intracortical remodeling in adult rat long bones after fatigue loading. Bone 23:275-281.

Biewener, A. A., S. M. Swartz, and J. E. A. Bertram. 1986. Bone modeling during growth: dynamic strain equilibrium in the chick tibiotarsus. Calcified Tissue International 39:390-395.

Bishop, P. J., C. W. Walmsley, M. J. Phillips, M. R. Quayle, C. A. Boisvert, and C. R. McHenry. 2015. Oldest pathology in a Tetrapod bone illuminates the origin of terrestrial vertebrates. PLoS ONE 10:e0125723.

Bordat, C. 1987. Étude Ultrastructurale de l'os des Vertèbres du Sélacien Scyliorhinus canicula L. Canadian Journal of Zoology 65:1435-1444.

Boyde, A. 2003. The real response of bone to exercise. Journal of Anatomy 203:173-189.

Brazeau, M. D. 2009. The braincase and jaws of a Devonian "Acanthodian" and modern gnathostome origins. Nature 457:305-308.

Brazeau, M. D., and V. de Winter. 2015. The hyoid arch and braincase anatomy of acanthodes support chondrichthyan affinity of "Acanthodians." Proceedings of the Royal Society of London B 282:20152210.

Brazeau, M. D., and M. Friedman. 2014. The characters of Palaeozoic jawed vertebrates. Zoological Journal of the Linnean Society 170:779-821.

Browne, M. A. E., M. T. Dean, I. H. S. Hall, A. D. McAdam, Monro., S. K., and J. I. Chisholm. 1999. A lithostratigraphical framework for the Carboniferous rocks of the Midland Valley of Scotland. British Geological Survey Research Report RR/99/ 07. British Geological Survey, Keyworth, Nottingham, U.K.

Burr, D. B. 1993. Remodeling and the repair of fatigue damage. Calcified Tissue International 53(Suppl. 1):S75-S81.

Burrow, C. J, S. Turner, J. G. Maisey, S. Desbiens, and R. F Miller. 2017. Spines of the stem chondrichthyan Doliodus latispinosus. Canadian Journal of Earth Sciences 54:1248-1262.

Capasso, L. L., F. Bacchia, N. Rabottini, B. M. Rothschild, and R. Mariani-Costantini. 1996. Fossil evidence of intraspecific aggressive behaviour of Devonian giant fishes (Arthrodira, Dinichthyidae). Journal of Paleopathology 8:153-160.

Chiari, Y., V Cahais, N. Galtier, and F. Delsuc. 2012. Phylogenomic analyses support the position of turtles as the sister group of birds and crocodiles (Archosauria). BMC Biology 10:1-14.

Clack, J. A., C. E. Bennett, D. K. Carpenter, S. J. Davies, N. C. Fraser, T. I. Kearsey, J. E. A. Marshall, D. Millward, B. K. A. Otoo, E. J. Reeves, A. J. Ross, M. Ruta, K. Z. Smithson, T. R. Smithson, S. A. Walsh. 2016. Phylogenetic and environmental context of a Tournaisian tetrapod fauna. Nature Ecology and Evolution 1:0002.

Conant, E. B. 1970. Regeneration in the African lungfish, Protopterus. Journal of Experimental Zoology 174:15-32.

Currey, J. D., M. N. Dean, and R. Shahar. 2017. Revisiting the links between bone remodelling and osteocytes: insights from across phyla. Biological Reviews 92:1702-1719.

Davesne, D., F. J. Meunier, A. D. Schmitt, M. Friedman, O. Otero, and R. B. J. Benson. 2019. The phylogenetic origin and evolution of acellular bone in teleost fishes: insights into osteocyte function in bone metabolism. Biological Reviews 94:1338-1363.

Denison, R. H. 1952. Early Devonian fishes from Utah, Part 1. Osteostraci. Fieldiana (Geology), 11:265-287.

De Smet, W. M.A. 1977. The fate of old bottle-nosed dolphins, Tursiops truncatus, in nature as revealed by the condition of their skeletons. Aquatic Mammals 5:78-86.

Doherty, A. H., C. K. Ghalambor, and S. W. Donahue. 2015. Evolutionary physiology of bone: bone metabolism in changing environments. Physiology 30:17-29.

Donoghue, P. C. J., and I. J. Sansom. 2002. Origin and early evolution of vertebrate skeletonization. Microscopy Research and Technique 59:352-372. 
Donoghue, P. C. J., I. J. Sansom, and J. P. Downs. 2006. Early evolution of vertebrate skeletal tissues and cellular interactions, and the canalization of skeletal development. Journal of Experimental Biology (Molecular and Developmental Evolution) 306B:278-294.

Downs, J. P., and P. C. J. Donoghue. 2009. Skeletal histology of Bothriolepis canadensis (Placodermi, Antiarchi) and evolution of the skeleton at the origin of jawed vertebrates. Journal of Morphology 270:1364-1380.

Egawa, S., S. Miura, H. Yokoyama, T. Endo, and K. Tamura. 2014. Growth and differentiation of a long bone in limb development, repair and regeneration. Development, Growth and Differentiation 56:410-424.

Felder, A. A., C. Phillips, H. Cornish, M. Cooke, J. R. Hutchinson, and M. Doube. 2017. Secondary osteons scale allometrically in mammalian humerus and femur. Royal Society Open Science 4:170431.

Fröbisch, N. B., C. Bickelmann, and F. Witzmann. 2014. Early evolution of limb regeneration in tetrapods: evidence from a 300-million-year-old amphibian. Proceedings of the Royal Society of London B 281:20141550.

Fröbisch, N. B., C. Bickelmann, J. C. Olori, and F. Witzmann. 2015. Deep-time evolution of regeneration and preaxial polarity in tetrapod limb development. Nature 527:231-234.

Frost, H. M. 1991. Some ABC's of skeletal pathophysiology. 6. The growth/modeling/remodeling distinction. Calcified Tissue International 49:301-302.

Galis, F., G. P. Wagner, and E. L. Jockusch. 2003. Why is limb regeneration possible in amphibians but not in reptiles, birds, and mammals? Evolution and Development 5:208-220.

Garvey, J. M., Z. Johanson, and A. Warren. 2005. Redescription of the pectoral fin and vertebral column of the rhizodontid fish Barameda decipiens from the lower Carboniferous of Australia. Journal of Vertebrate Paleontology 25:8-18.

Gerstenfeld, L. C., D. M. Cullinane, G. L. Barnes, D. T. Graves, and T. A. Einhorn. 2003. Fracture healing as a post-natal developmental process: molecular, spatial, and temporal aspects of its regulation. Journal of Cellular Biochemistry 88:873-884.

Gess, R. W., M. I. Coates, and B. S. Rubidge. 2006. A lamprey from the Devonian period of South Africa. Nature 443:981-984.

Geurtzen, K., F. Knopf, D. Wehner, L. F. A. Huitema, S. Schulte-Merker, and G. Weidinger. 2014. Mature osteoblasts dedifferentiate in response to traumatic bone injury in the zebrafish fin and skull. Development 141:2225-2234.

Giles, S., M. Rücklin, and P. C. J. Donoghue. 2013. Histology of "placoderm" dermal skeletons: implications for the nature of the ancestral gnathostome. Journal of Morphology 274:627-644.

Giles, S. M., Friedman, and M. D. Brazeau. 2015. Osteichthyan-like cranial conditions in an Early Devonian stem gnathostome. Nature 520:82-85.

Godfrey, S. J. 1988. Isolated tetrapod remains from the Carboniferous of West Virginia. Kirtlandia 43:27-36.

Godfrey, S. J. 1989. The postcranial skeletal anatomy of the Carboniferous tetrapod Greererpeton burkemorani Romer, 1969. Philosophical Transactions of the Royal Society of London B 323:75-133.

Goodman, A. H., and J. C. Rose. 1994. Assessment of systematic physiological perturbations from dental enamel hypoplasias and associated histological structures. Yearbook of Phyiscal Anthropology 33:59-110.

Goss, R. J., and M. W. Stagg. 1958. Regeneration of lower jaws in adult newts. Journal of Morphology 102:298-309.

Hall, B. K. 2005. Bones and cartilage, $1^{\text {st }}$ ed. Elsevier Academic Press, San Diego.

Hall, B. K. 2014. Endoskeleton/exo (dermal) skeleton-mesoderm/neural crest: two pair of problems and a shifting paradigm. Journal of Applied Ichthyology 30:608-615.

Hall, B. K. 2015. Bones and cartilage: developmental and evolutionary skeletal biology, $2^{\text {nd }}$ ed. Elsevier, London.
Hall, B. K, and J. Hanken. 1985. Repair of fractures jaws in the spotted salamander: do amphibians form secondary cartilage? Journal of Experimental Zoology 233:359-368.

Hall, B. K., and E. P. Witten. 2007. Plasticity of and transitions between skeletal tissues in vertebrate evolution and development. Pp. 13-56 in J. S. Anderson and H.-D. Sues, eds. Major transitions in vertebrate evolution. Indiana University Press, Bloomington

Halstead, L. B. 1969. Calcified tissues in the earliest vertebrates. Calcified Tissue Research 3:107-124.

Halstead, L. B. 1973. The heterostracan fishes. Biological Reviews 48:279-332.

Harris, S. 1978. Injuries to foxes (Vulpes vulpes) living in suburban london. Journal of Zoology 186:567-572.

Helfrich, M. H. 2003. Osteoclast diseases. Microscopy Research and Technique 61:514-532.

Herbst, E. C., and J. R. Hutchinson. 2018. New insights into the morphology of the Carboniferous tetrapod Crassigyrinus scoticus from computed tomography. Earth and Environmental Science Transactions of the Royal Society of Edinburgh 109:157-175.

Herman, B. C., L. Cardoso, R. J. Majeska, K. J. Jepsen, and M. B. Schaffler. 2010. Activation of bone remodeling after fatigue: differential response to linear microcracks and diffuse damage. Bone 47:766-772.

Hirasawa, T., and S. Kuratani. 2015. Evolution of the vertebrate skeleton: morphology, embryology, and development. Zoological Letters 1:1-17.

Hutchison, C., M. Pilote, and S. Roy. 2007. The axolotl limb: a model for bone development, regeneration and fracture healing. Bone 40:45-56.

Irwin, C. R., and M. W. J. Ferguson. 1986. Fracture repair of reptilian dermal bones: can reptiles form secondary cartilage? Journal of Anatomy 146:53-64.

Jackson, D. W., P. A. Lalor, H. M. Aberman, and T. M. Simon. 2001. Spontaneous repair of full-thickness defects of articular cartilage in a goat model. Journal of Bone and Joint Surgery 83A:53-64.

Jacobs, M. H. 1955. The traumatic bone cyst. Oral Surgery, Oral Medicine, Oral Pathology 8:940-949.

Jacyniak, K., R. P. McDonald, and M. K. Vickaryous. 2017. Tail regeneration and other phenomena of wound healing and tissue restoration in lizards. Journal of Experimental Biology 220:2858-2869.

Janvier, P., M. Arsenault, and S. Desbiens. 2004. Calcified cartilage in the paired fins of the osteostracan Escuminaspis laticeps (Traquair 1880), from the Late Devonian of Miguasha (Québec, Canada), with a consideration of the early evolution of the pectoral fin endoskeleton in vertebrates. Journal of Vertebrate Paleontology 24:773-779

Jenkins, M., S. Nimphius, N. H. Hart, P. Chivers, T. Rantalainen, K. Rueter, M. L. Borland, F. McIntyre, K. Stannage, and A. Siafarikas. 2018. Appendicular fracture epidemiology of children and adolescents: a 10-year case review in Western Australia (2005 to 2015). Archives of Osteoporosis 13(63):1-10.

Jiang, X., S. Iseki, R. E. Maxson, H. M. Sucov, and G. M. Morriss-Kay. 2002. Tissue origins and interactions in the mammalian skull vault. Developmental Biology 241:106-116.

Johanson, Z., M. Smith, A. Kearsley, P. Pilecki, E. Mark-Kurik, and C. Howard. 2013. Origins of bone repair in the armour of fossil fish: response to a deep wound by cells depositing dentine instead of dermal bone. Biology Letters 9:20130144.

Johansson, P. K. E., T. G. Douglass, and C. G. Lowe. 2004. Caudal spine replacement and histogenesis in the round stingray, Urobatis halleri. Bulletin of the Southern California Academy of Sciences 103:115-124

Keating, J. N., C. L. Marquart, and P. C. J. Donoghue. 2015. Histology of the heterostracan dermal skeleton: insight into the origin of the vertebrate mineralised skeleton. Journal of Morphology 276:657-680 
Keating, J. N., C. L. Marquart, F. Marone, and P. C. J. Donoghue. 2018. The nature of aspidin and the evolutionary origin of bone. Nature Ecology and Evolution 2:1501-1506.

Kemp, A. 2001. Consequences of traumatic injury in fossil and recent dipnoan dentitions. Journal of Vertebrate Paleontology 21(1):13-23.

Kemp, A. 2002a. Growth and hard tissue remodelling in the dentition of the Australian lungfish, Neoceratodus forsteri (Osteichthyes: Dipnoi). Journal of Zoology 257:219-235.

Kemp, A. 2002b. Hyaline tissue of thermally unaltered conodont elements and the enamel of vertebrates. Alcheringa 26:23-36.

Kemp, N. E., and J. H. Park. 1970. Regeneration of Lepidotrichia and Actinotrichia in the tailfin of the teleost Tilapia mossambica. Developmental Biology 22:321-342.

Khurana, J., F. Abdul-Karim, and J. V. M. G. Bovee. 2002. Osteochondroma. Pp. 234-236 in C. D. M. Fletcher, K. K. Unni, and F. Mertens, eds. World Health Organisation classification of tumours: pathology and genetics of tumours of soft tissue and bone. IARC Press, Lyon.

Kirschbaum, F., and F. J. Meunier. 1981. Experimental regeneration of the caudal skeleton of the glass knifefish, Eigenmannia virescens (Rhamphichthydae, Gymnotoidei). Journal of Morphology 168:121-135.

Knopf, F., C. Hammond, A. Chekuru, T.s Kurth, S. Hans, C. W. Weber, G. Mahatma, et al. 2011. Bone regenerates via dedifferentiation of osteoblasts in the zebrafish fin. Developmental Cell 20:713-724.

Kolmann, M. A., P. Urban, and A. P. Summers. 2018. Structure and function of the armored keel in piranhas, pacus, and their allies. Anatomical Record. doi: 10.1002/ar.23986.

Lebedev, O. A., E. Mark-Kurik, V. N. Karatajūtè-Talimaa, E. Luksevics, and A. Ivanov. 2009. Bite marks as evidence of predation in early vertebrates. Acta Zoologica 90:344-356.

Lingham-Soliar, T. 2004. Palaeopathology and injury in the extinct mosasaurs (Lepidosauromorpha, Squamata) and implications for modern reptiles. Lethaia 37:255-262.

Lu, S., L. Yang, H. Jiang, J. Chen, G. Yu, Z. Chen, X. Xia, and S. He. 2019. Bichirs employ similar genetic pathways for limb regeneration as are used in lungfish and salamanders. Gene 690:68-74.

Maas, M. C., and E. R. Dumont. 1999. Built to last: the structure, function, and evolution of primate dental enamel. Evolutionary Anthropology 8:133-152.

Marsell, R., and A. Einhorn. 2011. The biology of fracture healing. Injury 42:551-555.

Martin, R. B. 2003. Fatigue microdamage as an essential element of bone mechanics and biology. Calcified Tissue International 73:101-107.

Mayr, E. 1961. Cause and effect in biology. Science 134:1501-1506.

Meunier, F. J., and A. Huysseune. 1991. The concept of bone tissue in Osteichthyes. Netherlands Journal of Zoology 42:445-458.

Micklich, N., and S. Mentges. 2012. Fin ray fractures in messel fishes. Kaupia: Darmstädter Beiträge Zur Naturgeschichte 18:19-27.

Mitsiadis, T. A., C. De Bari, and I. About. 2008. Apoptosis in developmental and repair-related human tooth remodeling: a view from the inside. Experimental Cell Research 314:869-877.

Mitsiadis, T. A., and C. Rahiotis. 2004. Parallels between tooth development and repair: conserved molecular mechanisms following carious and dental injury. Journal of Dental Research 83:896-902.

Molnar, J. L., Rui, D., J. R. Hutchinson, and S. E. Pierce. 2018. Evolution of hindlimb muscle anatomy across the tetrapod water-to-land transition, including comparisons with forelimb anatomy. Anatomical Record. doi: 10.1002/ar.23997.

Moodie, R. L. 1917. Studies in paleopathology. I. General considerations of the evidences of pathological conditions found among fossil animals. Annals of Medical History 1:374-393.
Mori, S., and D. B. Burr. 1993. Increased intracortical remodeling following fatigue damage. Bone 14:103-109.

Moss, M. L. 1961. Studies of the acellular bone of teleost fish. I. Morphological and systematic variations. Acta Anatomica 46:343-362.

Moss, M. L. 1962. Studies of the acellular bone of teleost fish. II. Response to fracture under normal and alcemic conditions. Acta Anatomica 48:46-60.

Murdock, D. J. E., X. P. Dong, J. E. Repetski, F. Marone, M. Stampanoni, and P. C. J. Donoghue. 2013. The origin of conodonts and of vertebrate mineralized skeletons. Nature 502:546-549.

Nogueira, A. F., C. M. Costa, J. Lorena, R. N. Moreira, G. N. Frota-Lima, C. Furtado, M. Robinson, C. T. Amemiya, S. Darnet, and I. Schneider. 2016. Tetrapod limb and sarcopterygian fin regeneration share a core genetic programme. Nature Communications 7:13364.

Nunamaker, D. M. 2002. On bucked shins. AAEP Proceedings 48:76-89.

Panchen, A L. 1985. On the Amphibian Crassigyrinus scoticus Watson from the Carboniferous of Scotland. Philosophical Transactions of the Royal Society of London B 309:505-68.

Panchen, A. L., and T. R. Smithson. 1990. The pelvic girdle and hind limb of Crassigyrinus scoticus (Lydekker) from the Scottish Carboniferous and the origin of the tetrapod pelvic skeleton. Transactions of the Royal Society of Edinburgh (Earth Sciences) 81:31-44.

Pardo-Pérez, J. M., B. P. Kear, M. Gómez, M. Moroni, and E. E. Maxwell. 2018. Ichthyosaurian palaeopathology: evidence of injury and disease in fossil "fish lizards." Journal of Zoology 304:21-33.

Peignoux-Deville, J., C. Bordat, and B. Vidal. 1989. Demonstration of bone resorbing cells in elasmobranchs: comparison with osteoclasts. Tissue and Cell 21:925-933.

Peignoux-Deville, J., F. Lallier, and B. Vidal. 1982. Evidence for the presence of osseous tissue in dogfish vertebrae. Cell and Tissue Research 222:605-614.

Pineda, C., R. Espinosa, and A. Pena. 2009. Radiographic imaging in osteomyelitis: the role of plain radiography, computed tomography, ultrasonography, magnetic resonance imaging, and scintigraphy. Seminars in Plastic Surgery 23:80-89.

Pyron, R. A., and J. J. Wiens. 2011. A large-scale phylogeny of Amphibia including over 2800 species, and a revised classification of extant frogs, salamanders, and caecilians. Molecular Phylogenetics and Evolution 61:543-583.

Roth, A. J., G. S. Jones, and T. W. French. 2002. Incidence of naturally-healed fractures in the pectoral bones of North American accipiters. Journal of Raptor Research 36:229-230.

Rothschild, B. M., and L. D. Martin. 2006. Skeletal impact of disease. New Mexico Museum of Natural History and Science Bulletin 33.

Roy, S., and M. Lévesque. 2006. Limb regeneration in axolotl: is it superhealing? Scientific World Journal 6(S1):12-25.

Ruta, M., M. I. Coates, and D. L. J. Quicke. 2003. Early tetrapod relationships revisited. Biological Reviews 78:251-345.

Sansom, I. J., M. P. Smith, H. Armstrong, and M. M. Smith. 1992. Presence of the earliest vertebrate hard tissue in conodonts. Science 256:1308-1311.

Schindeler, A., McDonald, M. M., Bokko, P., and Little, D. G. 2008. Bone remodeling during fracture repair: the cellular picture. Seminars in Cell and Developmental Biology 19:459-466.

Schneider, C. A., W. S. Rasband, and K. Eliceiri. 2012. NIH Image to ImageJ: 25 years of image analysis. Nature Methods 9:671-675.

Schoch, R. R. 2001. Can metamorphosis be recognized in Palaeozoic amphibians? Neues Jahrbuch für Geologie und Paläontologie-Abhandlungen 220:335-367.

Schoch, R. R., and N. B. Fröbisch. 2006. Metamorphosis and neoteny: alternative pathways in an extinct amphibian clade. Evolution 60:1467-1475. 
Seref-Ferlengez, Z., J. Basta-Pljakic, O. D. Kennedy, C. J. Philemon, and M. B. Schaffler. 2014. Structural and mechanical repair of diffuse damage in cortical bone in vivo. Journal of Bone and Mineral Research 29:2537-2544.

Shapiro, F. 2008. Bone development and its relation to fracture repair. The role of mesenchymal osteoblasts and surface osteoblasts. European Cells and Materials 15:53-76.

Sharma, A. R., S. Jagga, S. Lee, and J. Nam. 2013. Interplay between cartilage and subchondral bone contributing to pathogenesis of osteoarthritis. International Journal of Molecular Sciences 14:19805-19830.

Sharp, E. L., and J. A. Clack. 2013. A review of the Carboniferous lungfish genus Ctenodus Agassiz, 1838 from the United Kingdom, with new data from an articulated specimen of Ctenodus interruptus Barkas, 1869. Earth and Environmental Science Transactions of the Royal Society of Edinburgh 104:169-204.

Shimada, A., T. Kawanishi, T. Kaneko, H. Yoshihara, T. Yano, K. Inohaya, M. Kinoshita, Y.O. Kamei, K. Tamura, and H. Takeda. 2013. Trunk exoskeleton in teleosts is mesodermal in origin. Nature Communications 4:1638-1639.

Shirley, B., M. Grohganz, M. Bestmann, and E. Jarochowska. 2018. Wear, tear and systematic repair: testing models of growth dynamics in conodonts with high-resolution imaging. Proceedings of the Royal Society of London B 285:20181614.

Smith, A. J., N. Cassidy, H. Perry, C. Begue-Kirn, J. V. Ruch, and H. Lesot. 1995. Reactionary dentinogenesis. International Journal of Developmental Biology 39:273-280.

Smith, M. M., and B. K. Hall. 1990. Development and evolutionary origins of vertebrate skeletogenic and odontogenic tissues. Biological Reviews of the Cambridge Philosophical Society 65:277-373.

Smithson, T. R. 1985. The morphology and relationships of the Carboniferous amphibian Eoherpeton watsoni Panchen. Zoological Journal of the Linnean Society 85:317-410.

Sousa, S., N. Afonso, A. Bensimon-Brito, M. Fonseca, M. Simoes, J. Leon, H. Roehl, M. L. Cancela, and A. Jacinto. 2011. Differentiated skeletal cells contribute to blastema formation during zebrafish fin regeneration. Development 138:3897-3905.

Sousa, S., F. Valerio, and A. Jacinto. 2012. A new zebrafish bone crush injury model. Biology Open 1:915-921.

Stilson, K. T., S. S. B. Hopkins, and E. B. Davis. 2016. Osteopathology in Rhinocerotidae from 50 million years to the present. PLoS ONE 11:e0146221.
Takeyama, K., M. Chatani, Y. Takano, and A. Kudo. 2014. In-vivo imaging of the fracture healing in medaka revealed two types of osteoclasts before and after the callus formation by osteoblasts. Developmental Biology 394:292-304.

Tanke, D. H., and P. J. Currie. 1998. Head-biting behavior in theropod dinosaurs: paleopathological evidence. Gaia 15: 167-184.

Tarlo, L. B. H. 1964. Psammosteiformes (Agnatha) - a review with descriptions of new material from the Lower Devonian of Poland: I. General part. Palaeontological Polonica 13:1-135.

Tiemann, A. H., and G. O. Hofmann. 2009. Principles of the therapy of bone infections in adult extremities: are there any new developments? Strategies in Trauma and Limb Reconstruction 4:57-64.

Turko, A. J., D. Kültz, D. Fudge, R. P. Croll, F. M. Smith, M. R. Stoyek, and P. A. Wright. 2017. Skeletal stiffening in an amphibious fish out of water is a response to increased body weight. Journal of Experimental Biology 220:3621-3631.

Turner, S., C. J. Burrow, H. P. Schultze, A. Blieck, W. E. Reif, C. B. Rexroad, P. Bultynck, and G. S. Nowlan. 2010. False teeth: conodont-vertebrate phylogenetic relationships revisited. Geodiversitas 32:545-594.

Uthgennant, B. A., M. H. Kramer, J. A. Hwu, B. Wopenka, and M. J. Silva. 2007. Skeletal self-repair: stress fracture healing by rapid formation and densification of woven bone. Journal of Bone and Mineral Research 22:1548-1556.

van der Vos, W., F. Witzmann, and N. B. Fröbisch. 2018. Tail regeneration in the Paleozoic tetrapod Microbrachis pelikani and comparison with extant salamanders and squamates. Journal of Zoology 304:34-44.

Warren, A., and R. Ptasznik. 2002. The earliest fractured tetrapod bone. Alcheringa: An Australasian Journal of Palaeontology 26:459-463

Witten, P. E., and A. Huysseune. 2009. Comparative view on mechanisms and functions of skeletal remodelling in teleost fish, with special emphasis on osteoclasts and their function. Biological Reviews 84:315-346.

Włodarski, K. H., A. Brodzikowska, and B. Kuzaka. 2014. Are chondroclasts and osteoclasts the same? Folia Biologica (Kraków) 62:135-142.

Zammit, M., and B. P. Kear. 2011. Healed bite marks on a Cretaceous ichthyosaur. Acta Palaeontologica Polonica 56:859-863.

Zhu, M., and X. Yu. 2002. A primitive fish close to the common ancestor of tetrapods and lungfish. Nature 418:767-770. 